\title{
MESOSCOPIC QUANTIFICATION OF CORTICAL ARCHITECTURE IN THE LIVING HUMAN BRAIN
}

\author{
○ Omer Faruk Gulban \\ Dep. of Cognitive Neuroscience \\ FPN, Maastricht University \\ Maastricht, Netherlands \\ - Konrad Wagstyl \\ Wellcome Centre for Human \\ Neuroimaging, UCL \\ London, UK
}
- Saskia Bollmann
Centre for Advanced Imaging
The University of Queensland
Brisbane, Australia
Rainer Goebel
Dep. of Cognitive Neuroscience FPN, Maastricht University Maastricht, Netherlands

\author{
$\odot$ Renzo Huber \\ Dep. of Cognitive Neuroscience \\ FPN, Maastricht University \\ Maastricht, Netherlands \\ Benedikt A. Poser \\ Dep. of Cognitive Neuroscience \\ FPN, Maastricht University \\ Maastricht, Netherlands
}

November 25, 2021

\begin{abstract}
Mesoscopic (0.1-0.5 mm) interrogation of the living human brain is critical for a comprehensive understanding of brain structure and function. However, in vivo techniques for mesoscopic imaging have been hampered by the sensitivity challenges of acquiring data at very high resolutions and the lack of analysis tools that can retain fine-scale detail while also accurately positioning measurements relative to the complex folded structure of the cerebral cortex. Here, we present an experimental dataset in which we image the anatomical structure of the visual and auditory cortices of five participants at $0.35 \times 0.35 \times 0.35 \mathrm{~mm}^{3}$ resolution. To analyze this challenging dataset, we design and implement two sets of novel methodology: a method for mitigating imaging artifacts related to blood motion and a suite of software tools for accurate quantification and visualization of the mesoscopic structure of the cortical surface. Applying these methods, we demonstrate the ability to clearly identify structures that are visible only at the mesoscopic scale, including cortical layers and intracortical blood vessels. We freely share our dataset and tools with the research community, thereby enabling investigations of fine-scale neurobiological structures in both the current and future datasets. Overall, our results demonstrate the viability of mesoscopic imaging as a quantitative tool for studying the living human brain.
\end{abstract}

Keywords in vivo $\cdot$ Human MRI $\cdot 7 \mathrm{~T} \cdot$ mesoscopic $\cdot \mathrm{T}_{2}{ }^{*} \cdot \mathrm{T}_{1} \cdot$ brain $\cdot$ layers $\cdot$ vessels $\cdot$ visual $\cdot$ auditory $\cdot$ cortex

\footnotetext{
${ }^{1}$ Corresponding author (https://orcid.org/0000-0001-7761-3727).

${ }^{2}$ Equal contribution.
} 


\section{Introduction}

A central goal in neuroscience is to achieve a comprehensive assessment of the structure of the living human brain. Centuries of work have been dedicated to characterizing the human brain from its macroscopic features (e.g., lobes, gyri, sulci) to its microscopic constituents (e.g., dendrites, cell bodies) (Finger et al., 2009, Ch. 1-10). The history of neuroscience has witnessed steady improvements in technologies for imaging the brain at increasing levels of detail (Bentivoglio \& Mazzarello, 2009). From the late $19^{\text {th }}$ to the early $20^{\text {th }}$ century, major advancements in tissue staining and photography opened new doors for measuring the human brain's cytoarchitecture (Geyer, 2013, Part 1), myeloarchitecture (Nieuwenhuys, 2013), fiber architecture (Kleinnijenhuis, 2014, Ch. 1), and angioarchitecture (Pfeifer, 1940).

In seminal works of neuroscience, it has been acknowledged that ex vivo experiments on animal and human brains are valuable but temporary necessities (Stahnisch, 2010). Fortunately, new technologies that enable study of the living human brain have emerged. The second half of the 20th century has brought computerized tomography (CT), positron emission tomography (PET), and magnetic resonance imaging (MRI) (Raichle, 2009a). Though these new technologies were far from the microscopic details provided by older methods, they quickly became indispensable due to their non-invasive nature. MRI has proven particularly useful for its flexibility to measure different tissue contrasts as well as hemodynamic measures of brain activity (Raichle, 2009b). Most recently, MRI at ultra-high magnetic field strength ( $\geq 7$ Tesla) has breached the mesoscopic scale (Barbier et al., 2002; Budde et al., 2011; Duyn et al., 2007; Federau \& Gallichan, 2016; Fukunaga et al., 2010; Huber et al., 2017; Kemper et al., 2018; Lüsebrink et al., 2021; Lüsebrink et al., 2017; Zwanenburg et al., 2011), which we define as resolutions between $0.1 \mathrm{~mm}$ and $0.5 \mathrm{~mm}$ (Edwards et al., 2018). However, in vivo mesoscopic MRI has not advanced beyond the proof-of-concept stage, and has not been incorporated into the toolkit of practicing neuroscientists. We suggest three main reasons why this is the case: (i) lack of practical high-resolution data acquisition protocols that provide sufficient coverage of the brain, (ii) lack of dedicated analysis tools that can optimally process mesoscopic imaging data, and (iii) lack of high-quality quantitative MRI datasets that can serve as benchmarks for the field.

In this paper, we deliver these missing elements - acquisition protocols, analysis tools, benchmark data - and demonstrate the viability of mesoscopic imaging as a quantitative tool for studying the living human brain. Our data are acquired using a practical adaptation of two conventional imaging sequences for performing measurements at the mesoscale. The data are acquired at the challenging resolution of $0.35 \mathrm{~mm}$ isotropic voxels and cover a substantial portion (approximately one-third) of the human brain. To compensate for low signal-to-noise ratio (SNR) and blood motion artifacts, we implement a compositing method that combines information across multiple phase-encoding-rotated acquisitions. To address the challenges of processing spatial detail at the mesoscopic scale, we develop new algorithms and image processing tools. One major innovation is a cortical flattening approach that accurately positions cortical measurements with respect to the 3D geometry of the cortical surface while minimizing data interpolation and computational burden. Finally, using the acquired dataset and the developed image processing tools, we demonstrate the feasibility of systematic study of the mesoscopic architecture of the living human brain. Specifically, we show how appropriate processing and visualization can provide qualitative and quantitative assessments of cortical substructures such as layers and vessels. All data, tools, and processing pipelines are freely shared with the community (see Section 5 .

\section{Methods}

\subsection{Data Acquisition}

\subsubsection{Session 1: $\mathbf{T}_{2}{ }^{*}$ with MEGRE}

In the first session, we acquired 3D multi-echo gradient recalled echo (MEGRE) images with bipolar readouts (Eckstein et al., 2018) to measure $\mathrm{T}_{2}{ }^{*}$ (see Table 1). The nominal image resolution was $0.35 \times 0.35 \times 0.35 \mathrm{~mm}^{3}$, and parameters included TR $=30 \mathrm{~ms}, \mathrm{TE}_{1-6}=[3.83,8.20,12.57,16.94,21.31,25.68] \mathrm{ms}, \mathrm{FA}=11^{\circ}, 576 \times 576 \times 104$ voxels, $\mathrm{FOV}=$ $20.16 \times 20.16 \times 3.64 \mathrm{~cm}^{3}$, elliptic k-space filling, 15 minutes duration, and no flow compensation. See Figure $1 \mathrm{~A}$ for the achieved coverage. In total, 4 successful MEGRE runs totalling 60 minutes were acquired in this scanning session. Between acquisitions of the 3D MEGRE we changed the phase-encoding direction by $90^{\circ}$ (right-left, anterior-posterior, left-right, posterior-anterior). These $90^{\circ}$ changes were introduced in order to control the direction of the blood motion artifacts (this artifact is called "spatial misregistration of the vascular flow" by Larson et al., 1990). As a result of this artifact, we see the vector component of the blood flow in the readout direction as a displacement (see Figure 2A-B). Note that the bipolar readouts have odd- and even-numbered echos acquired with opposite $\left(180^{\circ}\right)$ readout directions, which is known to introduce a slight spatial shift between their corresponding images due to the change in readout direction (Cohen-Adad, 2014). Nevertheless, we found that this shift is negligible compared to the flow artifact caused by the time elapsed between the encoding and readout stages. In addition to the MEGRE acquisition, a 
bioRxiv preprint doi: https://doi.org/10.1101/2021.11.25.470023; this version posted November 25, 2021. The copyright holder for this preprint (which was not certified by peer review) is the author/funder, who has granted bioRxiv a license to display the preprint in perpetuity. It is made available under aCC-BY-ND 4.0 International license.

Mesoscopic Quantification of Cortical Architecture in the Living Human Brain

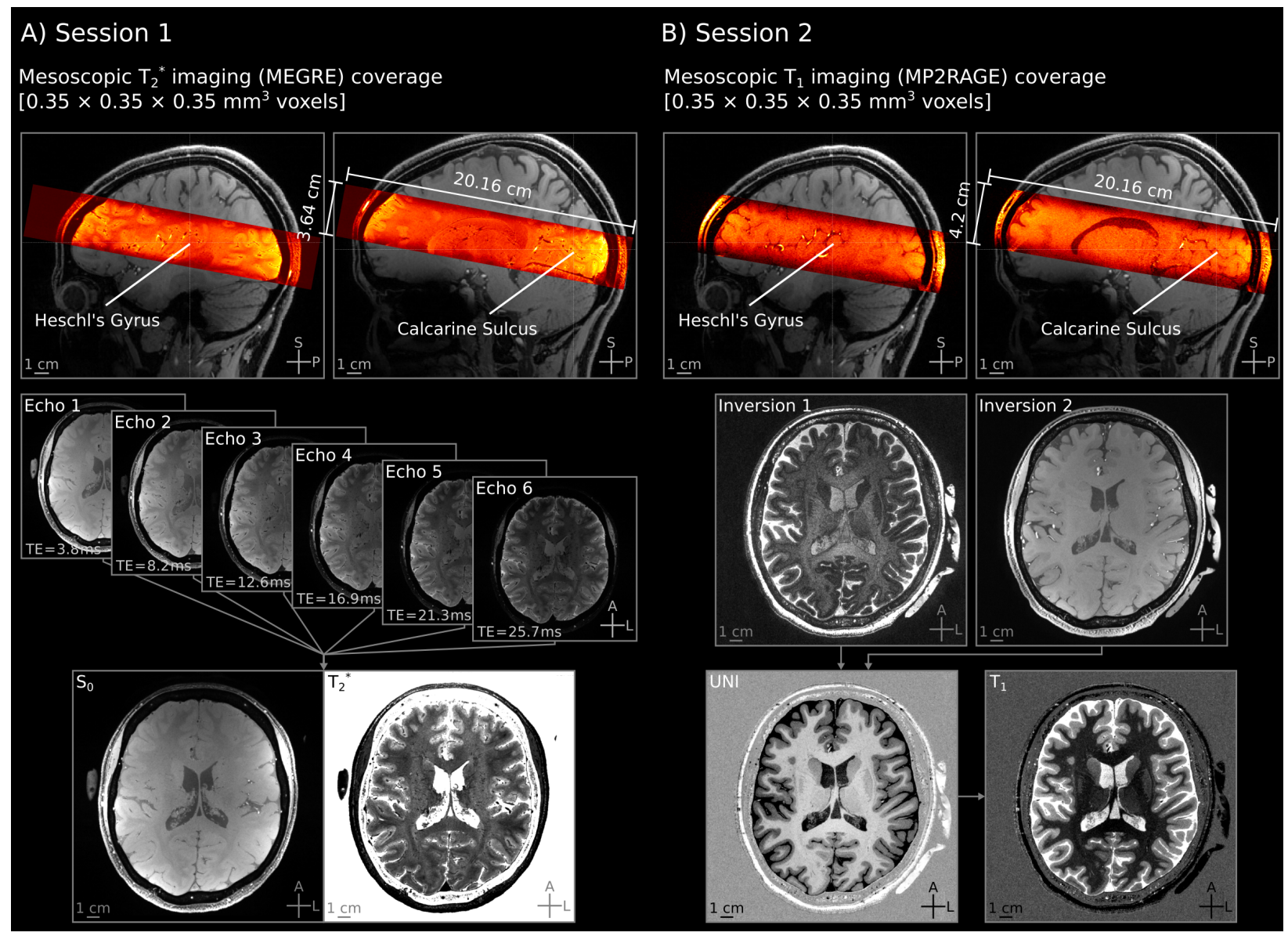

Figure 1: Spatial coverage and image quality of the MRI data acquisition. Here we show data quality for an example participant (sub-01) for the first (A) and second scan sessions (B) after preprocessing. High-resolution imaging slabs (in warm colors) are overlaid on top of the whole-brain lower-resolution image. The imaging slabs are positioned to cover both the calcarine sulci and Heschl's gyri (transverse temporal gyrus). Transversal images are averaged across runs. Despite the very high spatial resolution $(0.35 \mathrm{~mm}$ isotropic), SNR of our averaged images is high, allowing detection of cortical substructures even in the single echos in MEGRE and clearly distinguishing between gray and white matter in MP2RAGE. See Table 1 for acquisition parameters, and Section 5 for data availability and sequence parameter documents.

whole-brain magnetization prepared 2 rapid acquisition gradient echos (MP2RAGE) image (Marques et al., 2010) at 0.7 $\mathrm{mm}$ isotropic resolution was also acquired to provide whole-brain anatomical reference. Parameters included TR $=$ $5000 \mathrm{~ms}, \mathrm{TI}_{1-2}=[900,2750] \mathrm{ms}, \mathrm{TE}=2.46 \mathrm{~ms}, \mathrm{FA}_{1-2}=\left[5^{\circ}, 3^{\circ}\right], 320 \times 320 \times 240$ voxels, $\mathrm{FOV}=22.4 \times 22.4 \times 16.8$ $\mathrm{cm}^{3}$.

\subsubsection{Session 2: $\mathrm{T}_{1}$ with MP2RAGE}

In the second session, we acquired MP2RAGE images (Marques et al., 2010) (see Table 1). The nominal image resolution was equal to the $\mathrm{T}_{2}{ }^{*}$ images at $0.35 \times 0.35 \times 0.35 \mathrm{~mm}^{3}$, and parameters included TR $=5000 \mathrm{~ms}, \mathrm{TE}=2.91$ $\mathrm{ms}, \mathrm{TI}_{1-2}=[800,2700] \mathrm{ms}, \mathrm{FA}_{1-2}=\left[4^{\circ}, 5^{\circ}\right], 576 \times 576 \times 120$ voxels, $20.16 \times 20.16 \times 4.2 \mathrm{~cm}^{3}$ slab dimensions, and 10 minutes duration. See Figure $\mathbf{1} \mathbf{B}$ for the achieved coverage. In total, 6 successful MP2RAGE runs totalling 60 minutes were acquired in this scanning session. For completeness, we changed the phase-encoding direction by $90^{\circ}$ in each run similar to the MEGRE images acquired in Session 1. However, the effect of the flow-misencoding artifact is negligible because of the very short TE used in MP2RAGE images compared to MEGRE. 
Mesoscopic Quantification of Cortical Architecture in the Living Human Brain

Table 1: Acquisition parameters for the high-resolution scanning protocols.

\begin{tabular}{lll}
\hline Sequence & MEGRE & MP2RAGE \\
Voxel size & $0.35 \times 0.35 \times 0.35 \mathrm{~mm}^{3}$ & $0.35 \times 0.35 \times 0.35 \mathrm{~mm}^{3}$ \\
Field of view (FOV) & $201.6 \times 201.6 \times 36.4 \mathrm{~mm}^{3}$ & $201.6 \times 201.6 \times 42 \mathrm{~mm}^{3}$ \\
Slab dimensions & $576 \times 576 \times 104$ voxels & $576 \times 576 \times 120 \mathrm{voxels}$ \\
Bandwidth & $240 \mathrm{~Hz} / \mathrm{Px}$ & $250 \mathrm{~Hz} / \mathrm{Px}$ \\
TR & $30 \mathrm{~ms}$ & $5000 \mathrm{~ms}$ \\
TE & {$[3.83,8.20,12.57,16.94,21.31,25.68] \mathrm{ms}$} & $2.91 \mathrm{~ms}$ \\
Flip angle (FA) & $11^{\circ}$ & {$\left[4^{\circ}, 5^{\circ}\right]$} \\
TI & N/A & {$[800,2700] \mathrm{ms}$} \\
Read-out gradient mode & Bipolar & Monopolar \\
Phase partial Fourier & Off & $6 / 8$ \\
GRAPPA & 2 & 2 \\
Volume acquisition time & $15 \mathrm{~min}$ & $10 \mathrm{~min}$ \\
Total duration & $4 \times 15 \mathrm{~min}=60 \mathrm{~min}$ & $6 \times 10 \mathrm{~min}=60 \mathrm{~min}$ \\
\hline
\end{tabular}

\subsection{Data Analysis}

\subsection{1 $\mathrm{T}_{2}{ }^{*}$ Images (MEGRE)}

Each MEGRE image series consists of odd- and even-numbered echos with opposite readout direction (while phaseencoding was rotated by $90^{\circ}$ between acquisitions). Our processing pipeline aimed at reducing two sources of artifacts while improving the signal-to-noise ratio: (i) head motion across acquisitions, (ii) blood motion artifacts across echos. The processed data is then used to compute $\mathrm{T}_{2}{ }^{*}$ and $\mathrm{S}_{0}$ contrasts.

\subsubsection{Head motion correction}

We started by cropping our images to exclude the frontal brain regions (01_crop.py). This is done to reduce computational requirements for the upcoming steps. Then we averaged signal intensities across all echos per voxel (02_avg_echos.py). This averaged image improves SNR and is used only in the estimation of motion. We also upsampled both the original echos and the averaged images to $0.175 \mathrm{~mm}$ isotropic resolution with cubic interpolation; this allows fine-scale detail to be preserved during the motion correction process (Allen et al., 2021) (03_upsample.py). Head motion was estimated from the averaged images using rigid-body transformation ( 6 degrees of freedom) while using a manually defined brain mask covering our regions of interest; then, data were corrected using linear interpolation (04_motion_correct.py) (Yushkevich et al., 2006). Note that all runs are co-registered to the first MEGRE run. The estimated rigid body transformation matrices were applied to each upsampled echo separately (05_split_echos.py, 07_apply_reg.py, 08_merge_echos.py), resulting in a final set of brain volumes with nominal $0.175 \mathrm{~mm}$ resolution.

\subsubsection{Blood motion artifact mitigation}

After motion correction, we averaged the MEGRE images with the same phase-encoding axes for each echo $\left(\mathrm{PE}_{\mathrm{x}}\right.$ for right-left and left-right; $\mathrm{PE}_{\mathrm{y}}$ for anterior-posterior and posterior-anterior) to improve signal-to-noise ratio (09_average_same_PE_axes.py). This step is performed because the blood motion artifact direction is independent of the phase-encoding direction, and only dependent on the vector component of the blood flow along the readout axis (Larson et al., 1990). Then we composited a new image by selecting voxels from the $\mathrm{PE}_{\mathrm{x}}$ and $\mathrm{PE}_{\mathrm{y}}$ phase encoding axis images using a minimum operator (10_composite.py). Selecting the minimum intensity observed across the two images mitigates the blood motion artifact. Such image compositing operations are commonly used in the movie-making visual effects field (Brinkmann, 2008). In compositing, the main idea is to piece together a new image by using parts of multiple other images (see Figure 22). Since the blood motion artifact will be different across images with $90^{\circ}$ rotated phase-encoding axes $\left(\mathrm{PE}_{\mathrm{x}}\right.$ and $\left.\mathrm{PE}_{\mathrm{y}}\right)$, it is conceivable to composite a new image (i.e. a new set of echos) by selecting the signal of each voxel from the original set that is not affected by the artifact (a voxel affected by the artifact in $\mathrm{PE}_{\mathrm{x}}$ will not be affected in $\mathrm{PE}_{\mathrm{y}}$ ). As the last step to mitigate the residual blood motion artifacts, we detected those voxels that do not decay across echos (e.g. points on the decay curve showing a higher signal compared to the echo that comes before), and replaced its value with an average of the echo before and after (11_fix_nondecay.py). Note that our procedure is best viewed as mitigating as opposed to correcting the blood motion artifact: we are attempting to suppress the misencoded artery signal, not move it back to its correct location. 
bioRxiv preprint doi: https://doi.org/10.1101/2021.11.25.470023; this version posted November 25, 2021. The copyright holder for this preprint (which was not certified by peer review) is the author/funder, who has granted bioRxiv a license to display the preprint in perpetuity. It is made available under aCC-BY-ND 4.0 International license.

Mesoscopic Quantification of Cortical Architecture in the Living Human Brain

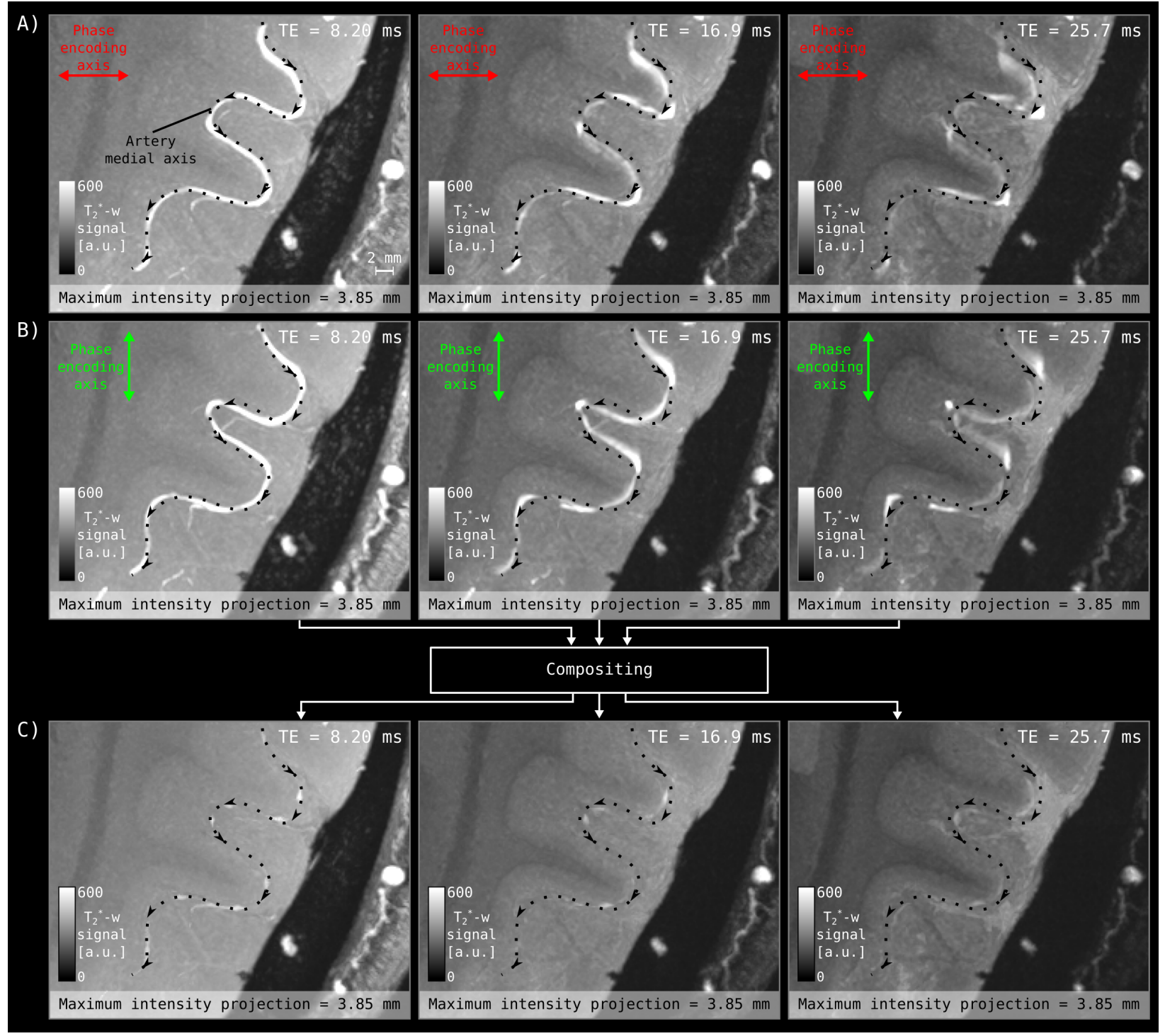

Figure 2: Compositing method to mitigate blood motion artifacts in $\mathbf{T}_{2}{ }^{*}$-weighted images. Here we show results from an example participant (sub-03). (A) Zoomed-in view of three of the six echos acquired using the right-left phase encoding axis. (B) Same echos acquired using anterior-posterior phase encoding axis. See that the blood motion artifact appears along the vector component of the blood flow along the readout axis (which is perpendicular to the phase-encoding axis). (C) Result of compositing the acquired images using the minimum operator. We show maximum intensity projection over a small slab (see the first panel for the scale bar) in order to enhance the visibility of the arterial signal. The dotted line superimposed on all images indicates the medial axis of an artery that was manually identified from the shortest TE $(3.83 \mathrm{~ms})$ image where the blood motion artifact is minimal. 


\subsection{4 $\mathrm{T}_{2}{ }^{*}$ fitting}

We fit a monoexponential decay function $\left(S_{T E}=S_{0} \cdot \exp \left(-T E / T_{2}^{*}\right)\right)$ to the processed MEGRE images by fitting a line to the logarithm of the signal using ordinary least-squares (12_fit_T2star.py) (Cohen-Adad et al., 2012) using Nibabel, Scipy, and Numpy (Brett et al., 2017; Jones et al., 2001; Van Der Walt et al., 2011). Note that in addition to providing an estimate of $T_{2}{ }^{*}$, this procedure also provides an estimate of $S_{0}$ (see Figure 1 A).

\section{$2.3 \quad T_{1}$ Images (MP2RAGE)}

Our processing strategy for the $\mathrm{T}_{1}$ images is aimed at correcting head motion across acquisitions while boosting signal-to-noise ratio through averaging.

\subsubsection{Head motion correction}

MP2RAGE images were processed similarly to the MEGRE images for the first two steps of cropping and upsampling (01_crop.py, 02_upsample.py). All runs are co-registered to the first MP2RAGE run using the INV2 contrast with the GREEDY (Yushkevich et al., 2016) registration algorithm (acquired from: https://github.com/pyushkevich/ greedy). We used the second MP2RAGE inversion time (INV2) contrast to drive registration because it has the best overall brain and non-brain signal-to-noise ratio. A brain mask focusing on our regions of interest was manually drawn in ITK-SNAP (Yushkevich et al., 2006) and used to constrain the registration cost metric. Registration was estimated using GREEDY rigid-body transformation (6 degrees of freedom) and data were corrected using linear interpolation (03_motion_correct.py). The estimated transformations were applied to all of the MP2RAGE contrasts (04_apply_reg.py). Finally, we computed the average across all motion-corrected images (05_average.py).

\subsubsection{Registration to $\mathrm{T}_{2}{ }^{*}$}

The MP2RAGE data were registered to the MEGRE using the second inversion time (INV2) contrast from the MP2RAGE and the $S_{0}$ image resulting from $T_{2}{ }^{*}$ fitting of the MEGRE. This choice was made due to the similarity of tissue contrast in these images. We used the GREEDY registration with 6 degrees of freedom and linear interpolation (06_register_to_T2s.py).

\subsection{Segmentation}

Accurate identification of gray and white matter is critical for proper interpretation of cortical architecture. We carefully segmented four main regions of interest in the registered MP2RAGE UNI images. These regions consisted of brain tissue in and around the calcarine sulcus and Heschl's gyrus in each hemisphere. To determine these regions, we centered a spherical mask at each of the relevant sulcal and gyral landmarks. We refer to these masks as scoops of interest (see Figure 34). We used an interactive intensity histogram thresholding method (Gulban et al., 2018) to obtain our initial tissue segmentation within each scoop of interest based on the MP2RAGE UNI contrast. After this step, each scoop of interest was manually edited by an expert (O.F.G.) and quality controlled for accurate and precise tissue segmentation (R.H.). The manual editing process took approximately 8 to 10 hours for each subject. We have chosen a laborious manual segmentation process over a fully automatic one because of the lack of optimized and validated segmentation tools for our very high resolution data. The resulting tissue segmentations are available as a part of our data repository and can be freely inspected. Note that we used the scoops of interest to focus our efforts on achieving the best segmentation for our regions of interest.

\subsection{Cortical Depths}

After completing the tissue segmentation, we used LayNii v.2.2.0 (Huber et al., 2021) to compute equi-volume cortical depths (Bok, 1959). Specifically, we prepared the segmentation input, i.e. the motion-corrected and averaged $\mathrm{T}_{1^{-}}$ weighted images (00_prep.py), and used the LN2_LAYERS program to compute equi-volume normalized cortical depth measurements for each gray matter voxel (01_layers.py). Note that the voxel-wise cortical depth metric computed in LN2_LAYERS ranges between 0 and 1 and reflect normalized units: cortical depth measurements (in $\mathrm{mm}$ ) are normalized by local cortical thickness measurements (in $\mathrm{mm}$ ) and then adjusted within this closed vector space to determine the equi-volume metric (see Figure 3B and Figure 4B) (this implementation is described in Huber et al., 2021). In addition, this program computes cortical curvature at each gray-matter voxel. See (Bok, 1959; Waehnert et al., 2014) for general references on the equi-volume principle of cortical layering.

To facilitate anatomical quantification, we also calculated distances for voxels that lie beyond the inner and outer gray-matter boundaries. This was done using LayNii program LN2_GEODISTANCE (02_beyond_gm_prep.py, 
bioRxiv preprint doi: https://doi.org/10.1101/2021.11.25.470023; this version posted November 25, 2021. The copyright holder for this preprint (which was not certified by peer review) is the author/funder, who has granted bioRxiv a license to display the preprint in perpetuity. It is made available under aCC-BY-ND 4.0 International license.

Mesoscopic Quantification of Cortical Architecture in the Living Human Brain
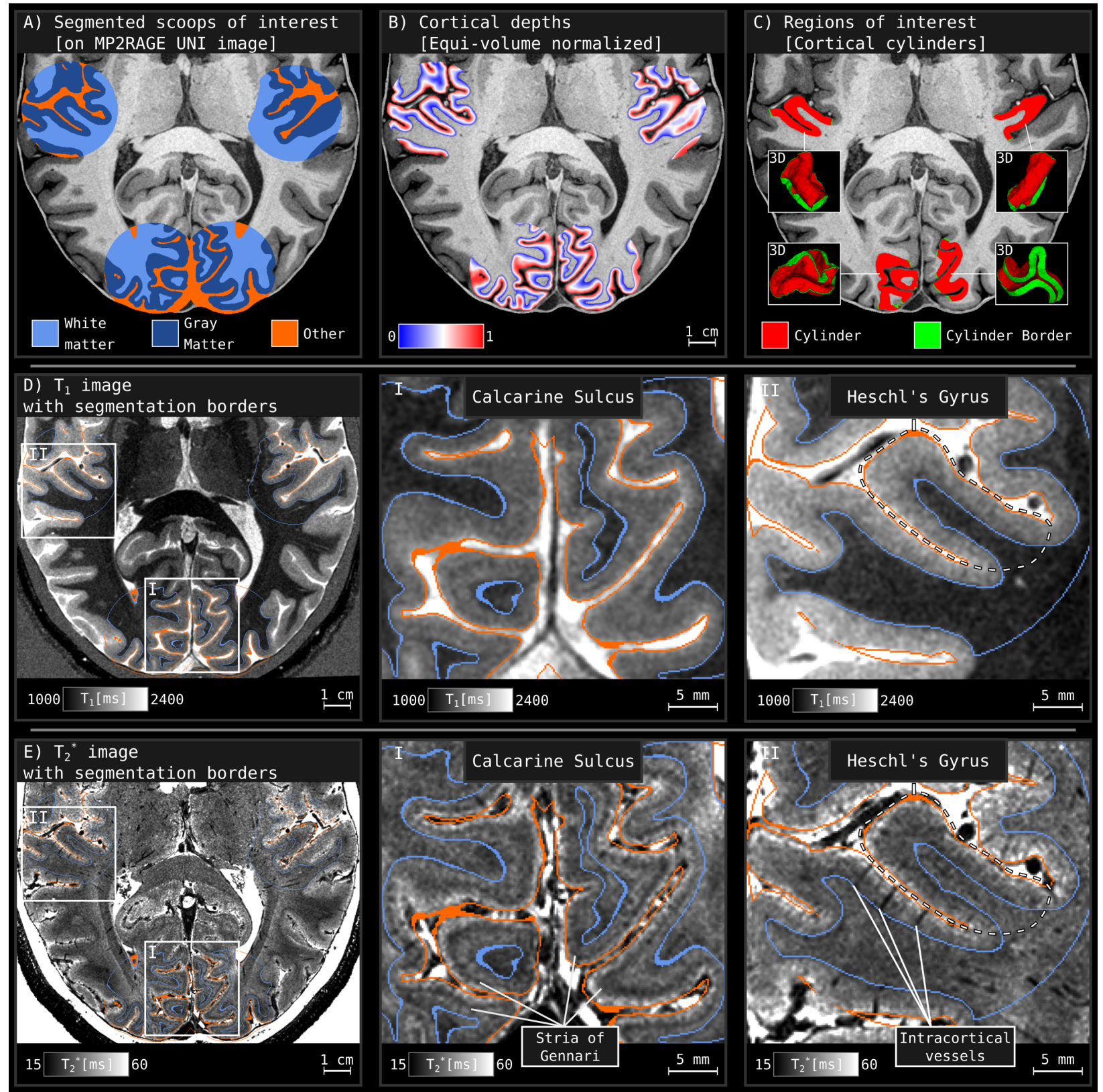

Figure 3: Segmentation, cortical depths, and regions of interest identified for an example subject (sub-04). (A-C) Major processing steps for characterizing our cortical regions of interest. The cortical cylinders in $\mathrm{C}$ were geodesically centered at the calcarine sulci and Heschl's gyri anatomical landmarks based on the middle gray-matter voxels. Careful manual tissue segmentation was performed, enabling extraction of gray-matter boundaries and cortical surface topology. (D-E) $\mathrm{T}_{1}$ and $\mathrm{T}_{2}{ }^{*}$ measurements in the regions of interest with overlaid gray-matter boundaries. Notice that the quality of the $\mathrm{T}_{2}{ }^{*}$ image allows visualization of fine-scale cortical substructures such as the Stria of Gennari and intracortical vessels. 
03_beyond_gm_distances.py). These beyond-gray-matter distances are quantified in mm units and we included voxels that are maximally $0.75 \mathrm{~mm}$ away from any gray matter border. Then, we created a collated distance file, combining the equi-volume depth metric together with the beyond-gray-matter distances (04_beyond_gm_collate.py, 05_beyond_gm_stitch.py). This file is used to plot cortical depth profiles together with voxels above and below the gray matter in Figures 7 710 (01_singlesub_depth_vs_T2star.py, 02_singlesub_depth_vs_T1.py, 01_group_depth_vs_T2star.py, 01_group_depth_vs_T1.py) using Matplotlib (Hunter, 2007).

\subsection{Patch Flattening}

To enable effective and accurate visualizations of the convoluted cortical surface, we designed a cortex flattening procedure that is optimized for partial brain coverage. We implemented this procedure as two separate programs: LN2_MULTILATERATE and LN2_PATCH_FLATTEN within LayNii v2.2.0 (Huber et al., 2021). First, we use the LN2_MULTILATERATE program to inject a flat coordinate system within our segmented regions (01_multilaterate.py). This program uses combinations of fast marching geodesic distance computations (Sethian, 1996) to impose a flat 2D coordinate system (which we refer to as UV coordinates, see Figure 44) on the convoluted cortex. UV coordinates are initially computed on gray matter voxels positioned mid-way through the cortical thickness. We select an origin voxel, and then define a geodesic disc (i.e. a disc with respect to the folded surface) around this voxel. Next, we isolate the disc perimeter voxels and find 4 points equally spaced along this perimeter using an iterative method. These four points are used to compute four distinct distances for each gray-matter voxel based on fast marching. Pairwise subtraction of these point-based distances yield two separate signed distance fields. These signed distance fields form our $\mathrm{UV}$ coordinates (i.e., right minus left yields $\mathrm{U}$ and up minus down yields $\mathrm{V}$ ). Then the coordinates are propagated to the rest of the cortical thickness to cover the whole cortical depth (see Figure $3 \mathrm{C}$ ). Finally, we use the LN2_PATCH_FLATTEN program to combine the voxel-wise UV coordinates with the equi-volume cortical depth measurements (abbreviated as D coordinate, see Figure 4B) to generate fully flattened and parameterized cortical brain chunks (02_patch_flatten.py). The end result of this procedure is a full continuous mapping between flat cortex space (UVD) and the original folded cortex space (XYZ). In essence, we are able to quickly determine UVD coordinates for any point in XYZ space, and vice versa. This mapping allows us to accurately and efficiently plot data from our regions of interest in "virtual Petri dishes", in which we visualize the cortical landscape across the cortical surface and through cortical depth (see Figure $4 \mathrm{~B}$ ). We note that a conceptual predecessor of our mapping approach with a completely different implementation is shown in Kemper et al. (2018). In addition, we are able to rapidly change the resolution of the virtual Petri dish with respect to cortical depth (e.g. from 11 to 1000 bins) or cortical landscape (e.g. from $100 \times 100$ to $2000 \times 2000$ bins to represent the $30 \mathrm{~mm}$ diameter cylindrical surface), without incurring substantial computational overhead. To highlight the effectiveness of the virtual Petri dishes for interactively surveying mesoscopic data, we provide example animations at https://osf .io/n5bj7 under Supplementary Figures folder. To summarize data across depths, in some cases we compute a median projection by calculating the median value observed across depth (03_median_projection.py) (see Figure 5A-B).

\section{Results}

\subsection{Mitigation of Blood Motion Artifact Using Compositing}

We acquired images of the living human brain at $0.35 \times 0.35 \times 0.35 \mathrm{~mm}^{3}$ resolution while covering the visual and auditory cortices of five participants. Our processing focused on ensuring that the fine-scale details in our images are retained while improving our SNR. However, we addressed another major high-resolution imaging problem. Even in the absence of head motion, blood is moving within the cerebral vessels. Therefore, collecting in vivo data at mesoscopic resolution requires detailed consideration of moving particles. The combination of acquisition parameters, blood flow velocity, and the orientation of vessels with regards to the spatial encoding directions in MRI results in significant spatial shifts of the signal associated with large arteries (Wehrli, 1990). This artifact is called "spatial misregistration of the vascular flow" and its underlying theory is detailed in (Larson et al., 1990). For brevity, we refer to this phenomenon simply as blood motion artifact. The blood motion artifact obstructs measurement of nearby cortical tissue (up to several millimeters away), and may lead to erroneous interpretation of the local tissue microstructure (e.g. when the signal from a large artery shifts onto cortical gray matter).

We observe the blood motion artifact in our MEGRE images at an unprecedented level of detail. In Figure 2A-B, we show that this artifact exhibits itself as a bright signal moving outside of the arterial location following the vector component of blood flow along the readout axis. This is a major problem for gray matter $\mathrm{T}_{2}{ }^{*}$ measurements because the blood motion artifact causes an artifactual inflation of $\mathrm{T}_{2}{ }^{*}$ in nearby gray matter tissue. By performing $90^{\circ}$ phaseencoding axis rotations across multiple data acquisitions, we were able to change the direction of the blood motion 
artifact. Note that maximum intensity projection over $3.85 \mathrm{~mm}$ is used to highlight the artifact in Figure 2C. However, the artifact can be easily observed in single slices using interactive data browsers (see Section 5 .

We developed a simple artifact mitigation method that does not incur extra scanning time nor require major assumptions. As we need to increase SNR by taking into account the multiple data acquisitions in any case, we leverage the dependence between the artifact's direction and the phase-encoding direction by compositing two $90^{\circ}$-rotated phaseencoding axis images into a single image via a minimum operation. As a consequence of this method, the bright arterial signal can to a large extent be removed from the single-echo images (see Figure 2C). The residual bright spots visible in the composited image are voxels where the artifact exhibits itself in such a way that $90^{\circ}$ phase-encoding rotation does not alter the artifactual brightness. Note that even at an early $8.2 \mathrm{~ms}$ echo time, $90^{\circ}$ phase-encoding axis rotated images show different artery paths. This means that the true location of the large arteries $(\sim 1 \mathrm{~mm}$ diameter $)$ is very hard to identify from a single-echo image. However, the true location of the artery can be estimated by considering the earliest echos. The exact flow direction is hard to understand from single slices, but the artery can be traced back towards the main cerebral arteries to deduce the flow direction. We have manually indicated the estimated artery location and designated it with dotted lines with arrows in Figure 2 The arrows on the dotted line indicate flow direction.

Figure 2 shows that our blood motion artifact mitigation method is effective. It can be seen that we obtain cleaner single echos for non-artery tissues and suppress the arterial signal. This is advantageous for $\mathrm{T}_{2}{ }^{*}$ fitting within the gray matter because the fit will not be affected by strong artifactual artery-induced jumps in the measured decay curves (Wehrli, 1990). Note that by applying a minimum operator across independent acquisitions, we are also enhancing overall SNR, as variability in signal intensity within a given tissue type is reduced. From a global $\mathrm{T}_{2}{ }^{*}$ measurement perspective, the blood motion artifact has a fairly minor impact on the distribution of $\mathrm{T}_{2}{ }^{*}$ values, because the large arteries (> $1 \mathrm{~mm}$ diameter) supply limited portions of the brain compared to the rest of the gray- and white-matter tissue. However, from a local perspective (one which mesoscopic imaging promotes), not accounting for the blood motion artifact risks greatly inflated $\mathrm{T}_{2}{ }^{*}$ values.

\subsection{Accurate Cortical Flattening at the Mesoscopic Scale}

Human cerebral cortex is extremely convoluted. To understand mesoscopic cortical architecture in our data, we developed a novel set of geometric tools that enable parameterization of cortical surface topology and cortical flattening while preserving all fine-scale detail present in the high-resolution anatomical volumes. As a result of these tools, we are able to transform the folded cortex into a flattened volume format, which enables not only looking through the cortical depths but also looking across the mesoscopic landscape (see Figure $4 \mathrm{C}-\mathrm{D}$ ). Although it is inevitable that projecting the folded cortex into a flattened format will cause local distortions (Fischl, Sereno, \& Dale, 1999; Fischl, Sereno, Tootell, et al., 1999), Figure $4 \mathrm{E}$ shows that our cortical patch flattening method has desirable distortion characteristics compared to the conventional triangular mesh based tools shown in (Kay et al., 2019). Specifically, our method is able to minimize distortion with respect to the entire cortical thickness and distributes distortion evenly throughout the cortical patch. Moreover, by avoiding explicit construction of triangular meshes, we avoid time-consuming mesh generation and the loss of resolution that can occur when resampling data to a new space. Our approach enables the values of the original high-resolution folded brain to be organized into a flattened cortical representation efficiently and at arbitrary desired resolution.

\subsection{Intracortical Vessels and Layers Revealed in Flattened Cortices}

Given the high quality of our $0.35 \mathrm{~mm}$ acquisition and analysis approach, we find that simple inspections of the data reveal clearly visible properties of intracortical vessels. For the first time, by exploiting the mesoscopic image processing tools we have developed, we are able to visualize penetrating vessel trunks over the cortical surface similar to what is seen with invasive measurement techniques (Duvernoy et al., 1981, Fig. 64). Figure 5 shows that there are multitude of local $\mathrm{T}_{2}{ }^{*}$ signal decreases across the cortical surface. We have manually labeled the most visible dips similar to (Duvernoy et al., 1981) in this initial investigation; however, future studies can improve the detection of such intracortical vessels by developing automatic methods similar to (Bernier et al., 2018; Huck et al., 2019). Following Duvernoy's nomenclature, we call these intracortical vessels, and they most likely belong to groups 4 and 5 of the intracortical veins. The labeled intracortical veins in our images often penetrate through the majority of the cortical thickness, as expected. Examples of intracortical veins can be observed in the original 3D folded brain space in Figure $3 \mathrm{E}$.

Browsing superficial gray matter reveals large differences between $T_{2}{ }^{*}$ and $T_{1}$ measurements due to the presence of pial vessels that lie above the cortex. Figure 6A shows measurements sampled from the superficial depth in and around the calcarine sulcus. Branching impressions of the pial vessels can easily be seen as contiguous low $\mathrm{T}_{2}{ }^{*}$ regions. Comparing the $T_{2}{ }^{*}$ data with $T_{1}$ reveals that the $T_{1}$ maps do not show similarly visible impressions. This might be due 
bioRxiv preprint doi: https://doi.org/10.1101/2021.11.25.470023; this version posted November 25, 2021. The copyright holder for this preprint (which was not certified by peer review) is the author/funder, who has granted bioRxiv a license to display the preprint in perpetuity. It is made available under aCC-BY-ND 4.0 International license.

Mesoscopic Quantification of Cortical Architecture in the Living Human Brain

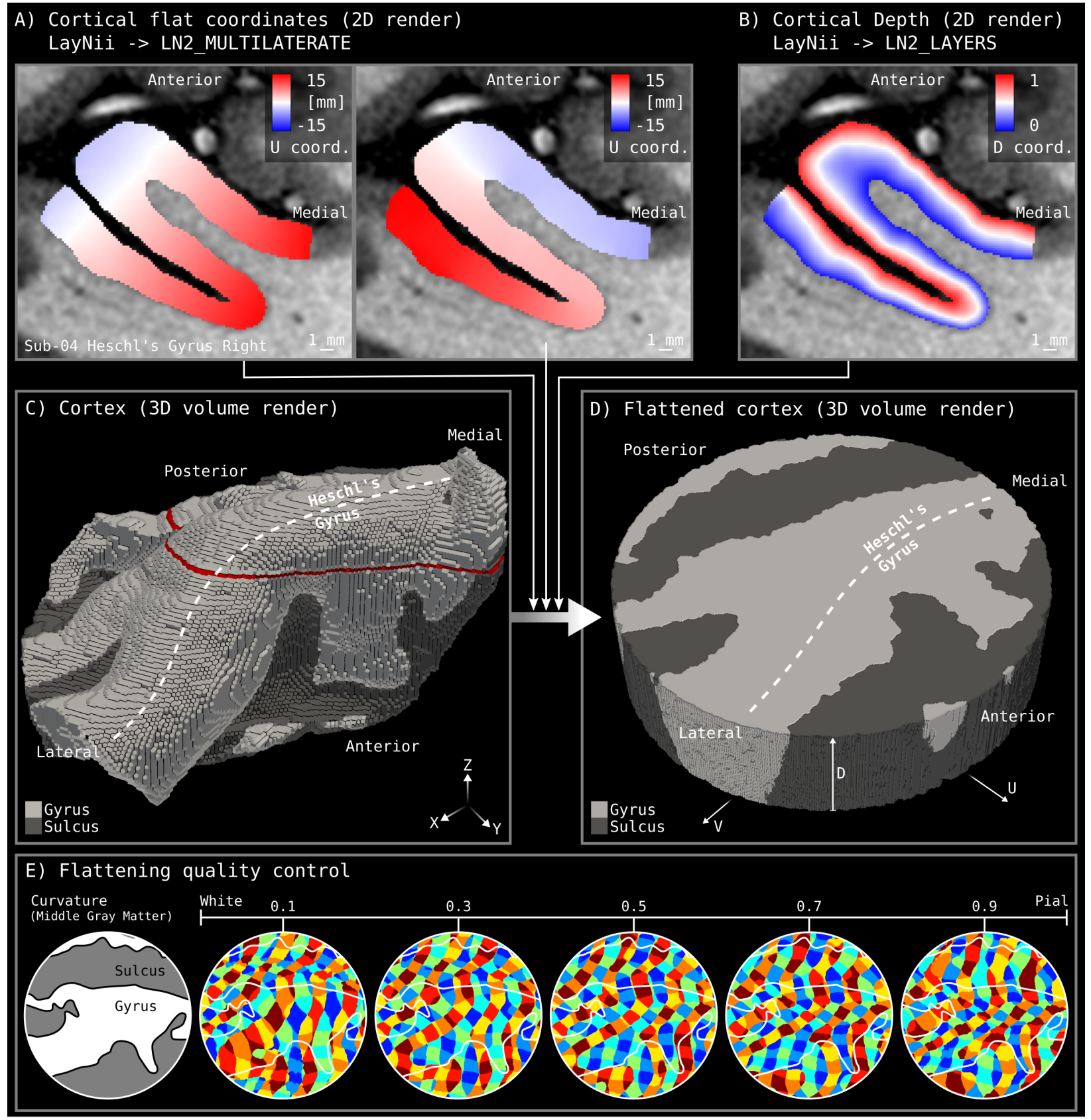

Figure 4: Demonstration of cortical flattening and depth assignment. Cortical cylinders in the form of virtual Petri dishes are used for flattening our regions of interest. A cylinder is centered at our anatomical landmarks and its radius is set to $15 \mathrm{~mm}$. The cylinder height covers the whole cortical thickness. (A) Cortical flat coordinates visualized for a 2D slice. (B) Cortical equi-volume depth assignment for the same slice. (C) Structure of cortical cylinder in original 3D folded brain space (XYZ coordinates). The red line indicates the location of the 2D slice in panels A and B. (D) Structure of cortical cylinder after flattening (UVD coordinates). (E) Assessment of flattening distortion. Here we use the 'surface voxels' technique (Kay et al., 2019, Fig. 4) and construct a synthetic test volume consisting of $2.1 \mathrm{~mm}$ isotropic voxels and visualize the resulting positions of these voxels in the flattened visualization. Each individual colorful patch corresponds to the cross-section of exactly one $2.1 \mathrm{~mm}$ cube. Compared to the extensive shrinkage in sulci and expansion in gyri shown in (Kay et al., 2019, Fig. 4B), the amount of distortion is fairly modest and equally distributed across gyri and sulci. 


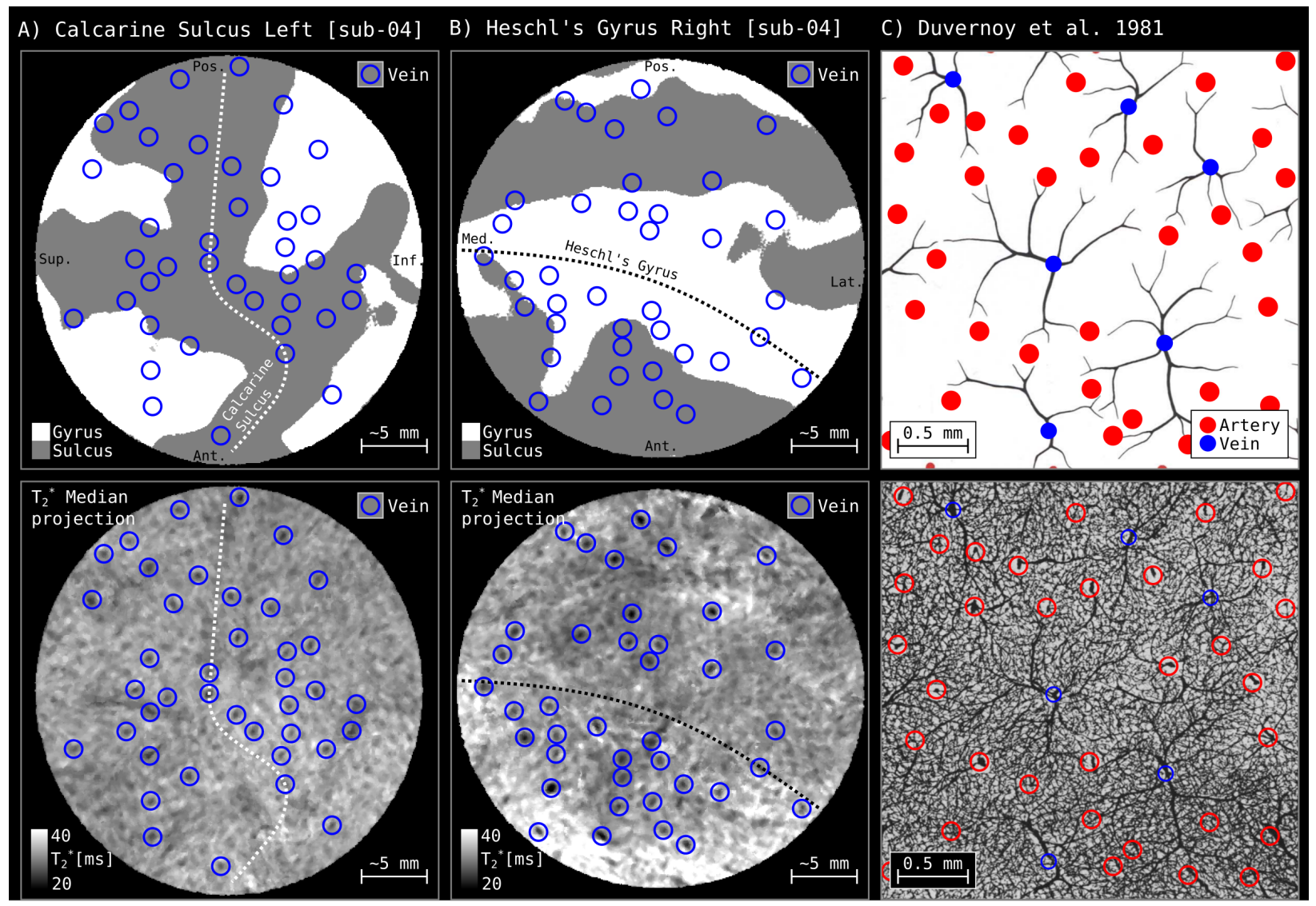

Figure 5: Comparison between in vivo flattened cortical surface representation of $\mathbf{T}_{2}{ }^{*}$ measurements and ink-gelatin perfusion images from Duvernoy et al. (1981). (A-B) Curvature (top) and median-projected $\mathrm{T}_{2}{ }^{*}$ measurements (bottom) for two example cortical patches. Median projection is performed to summarize all cortical depths into a single image. (C) Manually labeled schematic (top) and original ink injection images (bottom) for a sample patch of tissue as reproduced from Duvernoy et al. (1981).

to the deoxyhemoglobin in the vessels affecting the $\mathrm{T}_{2}{ }^{*}$ signal outside of their trunks (Bause et al., 2020), while in $\mathrm{T}_{1}$ maps it is mostly indistinguishable from the neighboring gray matter. Cross-sections through these cortical cylinders reveal the extent of the pial vessel effects on $\mathrm{T}_{2}{ }^{*}$ (Figure 6B-C). It can be seen that the extent of darkening can be up to approximately $1 / 4$ of the cortical depth. In addition, the penetrating blood vessels are clearly visible as vertical bands.

In addition to the clearly visible vascular impressions across the cortical surface, laminar structures can be seen as horizontal features in Figure 6B-C. It can be seen that there are lower $\mathrm{T}_{2}{ }^{*}$ values around the middle of the cortical thickness. This structure is likely the stria of Gennari (Fulton, 1937; Gennari, 1782; Glickstein \& Rizzolatti, 1984). However, we refrain from attributing this laminar structure only to neuronal layers because Duvernoy et al. (1981) and Pfeifer (1940) showed that there are angioarchitectonic layers within the cortex as well.

\subsection{MRI Signal Across Cortical Depths}

\subsubsection{Empirical $T_{2}{ }^{*}$ cortical depth profiles}

One of the types of anatomical data we acquired are quantitative $T_{2}{ }^{*}$ measurements. Such measurements are valuable because optimization and interpretation of several MRI sequences such as $\mathrm{T}_{2}{ }^{*}$-weighted anatomical or functional imaging depend on the reported gray matter $\mathrm{T}_{2}{ }^{*}$ values (Cohen-Adad et al., 2012; Deistung et al., 2013; Markuerkiaga et al., 2021; Marques et al., 2017). For instance, high-resolution functional imaging studies make use of the $\mathrm{T}_{2}{ }^{*}$ values across cortical depths to model unwanted vein effects. Therefore, the unprecedented in vivo quantitative imaging resolution of our dataset is highly valuable. In addition, optimal $\mathrm{T}_{2}{ }^{*}$-weighting parameters are known to vary across brain regions, and previously reported gray matter $\mathrm{T}_{2}{ }^{*}$ values are biased towards the occipital cortex (Peters et al., 2007). 
bioRxiv preprint doi: https://doi.org/10.1101/2021.11.25.470023; this version posted November 25, 2021. The copyright holder for this preprint (which was not certified by peer review) is the author/funder, who has granted bioRxiv a license to display the preprint in perpetuity. It is made available under aCC-BY-ND 4.0 International license.

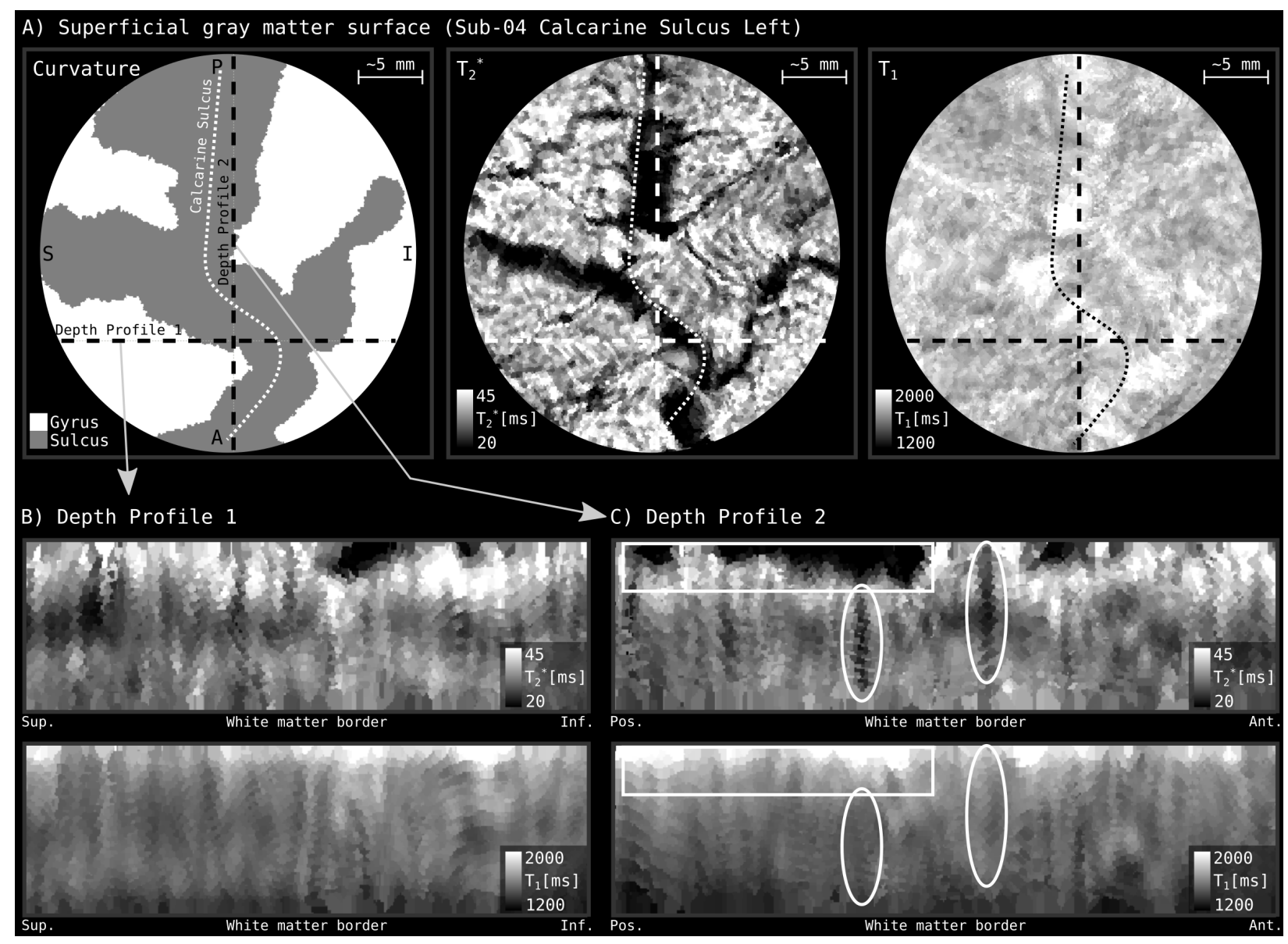

Figure 6: Comparison of flattened $T_{2}{ }^{*}$ and $T_{1}$ measurements in a single subject (sub-04). (A) Measurements across the cortical surface at the superficial cortical depth. The color associated with each pixel in these images come from exactly one folded brain voxel (processed at $0.175 \mathrm{~mm}$ isotropic resolution). $\mathrm{T}_{2}{ }^{*}$ effects of the pial vessels can be seen as dark impressions in the middle image. (B-C), Measurements for two different cross-sections of cortex. Laminar variations, pial vessel effects (rectangles), and intracortical veins (ellipses) are all visible.

Therefore, we report gray matter $\mathrm{T}_{2}{ }^{*}$ values across cortical depths for both the visual and auditory cortices to form the quantitative basis upon which further optimization and interpretation work can be built.

We plotted single-subject $\mathrm{T}_{2}{ }^{*}$ measurements across cortical depths for the calcarine sulci and Heschl's gyri in both hemispheres in Figure 7. It can be seen that there is a dip in $\mathrm{T}_{2}{ }^{*}$ values at the middle depth of the gray matter in the calcarine sulci, while a similar dip is not visible for Heschl's gyri. This observation follows what is visible to the naked eye in Figure $3 \mathbf{E}$, namely there is a layer of low $\mathrm{T}_{2}{ }^{*}$ values within the calcarine sulcus (Barbier et al., 2002; Budde et al., 2011; Duyn et al., 2007; Federau \& Gallichan, 2016; Fukunaga et al., 2010; Kemper et al., 2018; Zwanenburg et al., 2011). This observation holds for every subject and is qualitatively consistent across the left and right hemispheres of each subject. It can be said that average $\mathrm{T}_{2}{ }^{*}$ is biologically perturbed across cortical depths.

Looking at the group results in Figure 8 , we observe that $\mathrm{T}_{2}{ }^{*}$ variance increases towards the superficial depths in every subject. This could be due to the increased partial voluming with both pial vessels (which causes low $\mathrm{T}_{2}{ }^{*}$ ) and CSF (which causes high $\mathrm{T}_{2}{ }^{*}$ ) that lie above gray matter, and indicates $\mathrm{T}_{2}{ }^{*}$ is not only neurobiologically biased across depth but also heteroskedastic. Thus, when modelling cortical MRI signals (Havlicek \& Uludag, 2020; Markuerkiaga et al., 2021; Uludag et al., 2009), care must be taken not only to account for varying $\mathrm{T}_{2}{ }^{*}$ but also accounting for the varying amounts of $\mathrm{T}_{2}{ }^{*}$ variance across cortical depths. In contrast, when considering the white-matter voxels below the gray matter, variance appears to be similar to the deep gray-matter voxels. Overall, we observe slightly reduced $\mathrm{T}_{2}{ }^{*}$ values in white matter compared to gray matter, which could be attributed to the increased myelin content in white matter as well as increased iron content in U-fibers (Kirilina et al., 2020). 
bioRxiv preprint doi: https://doi.org/10.1101/2021.11.25.470023; this version posted November 25, 2021. The copyright holder for this preprint (which was not certified by peer review) is the author/funder, who has granted bioRxiv a license to display the preprint in perpetuity. It is made available under aCC-BY-ND 4.0 International license.

Mesoscopic Quantification of Cortical Architecture in the Living Human Brain

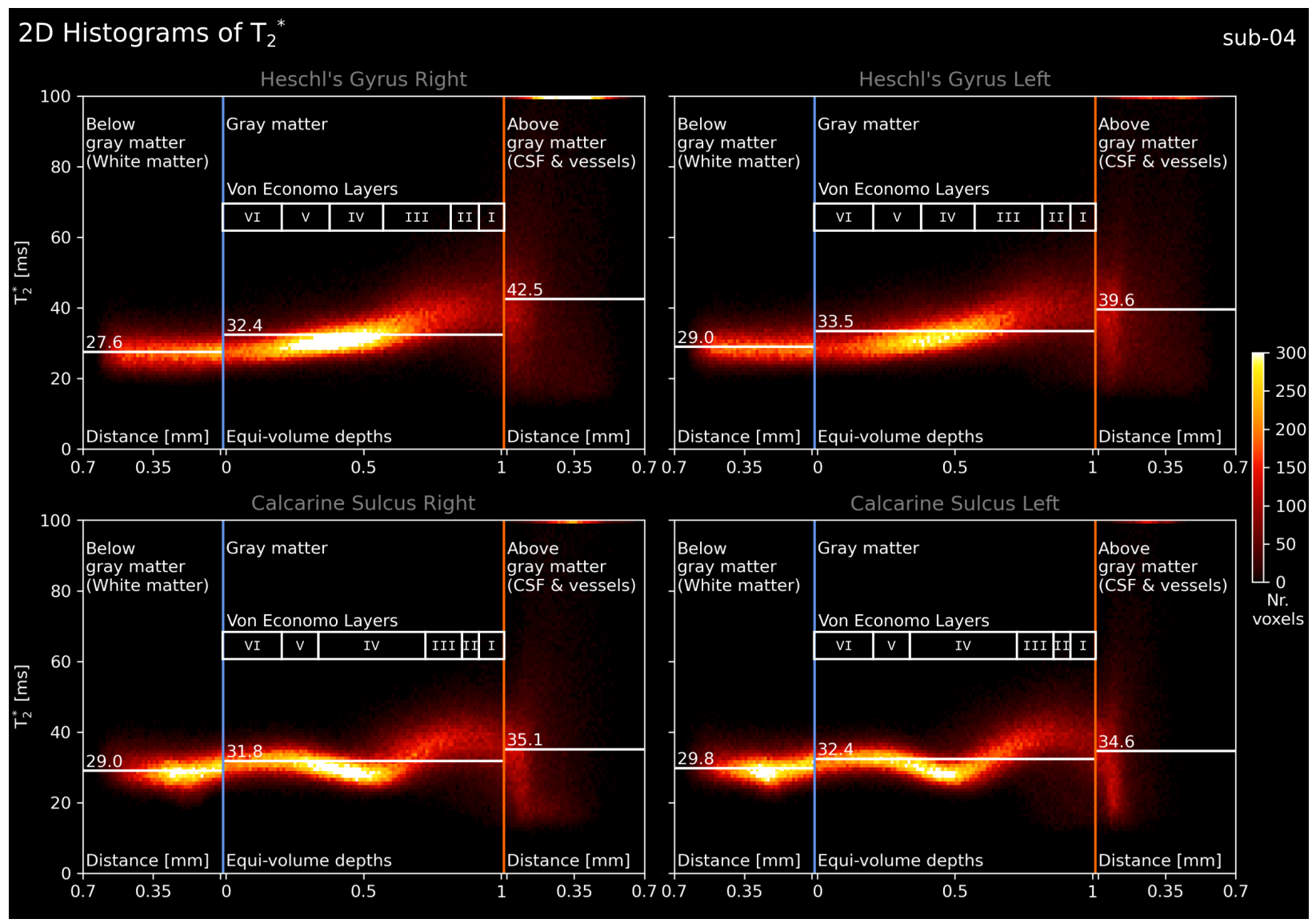

Figure 7: 2D histograms of $\mathbf{T}_{2}{ }^{*}$ as a function of cortical depth for a single subject (sub-04). The vertical lines show gray matter borders: blue for the inner gray-matter border and orange for the outer gray-matter border (see Figure 3D-E). Horizontal white lines show the average $\mathrm{T}_{2}{ }^{*}$ for different tissue sections: below gray matter, gray matter, and above gray matter. Note the topmost bins within the above gray-matter section showing very high $\mathrm{T}_{2}{ }^{*}$ voxels that are out of range. See figure supplements showing each individual at https://osf .io/n5bj7 under Supplementary Figures folder.

\subsubsection{Empirical $T_{1}$ cortical depth profiles}

We also acquired quantitative $T_{1}$ values using the MP2RAGE sequence (Marques et al., 2010). $T_{1}$-weighted images are often used for segmentation of brain tissue. $T_{1}$ contrast is also known to be related to myelination and therefore used for delineating areal borders (Cohen-Adad et al., 2012; Deistung et al., 2013; Dick et al., 2012; Haast et al., 2016; Marques et al., 2017). While there have been efforts to acquire mesoscopic resolution $T_{1}$ and $T_{1}$-weighted images in the past (Federau \& Gallichan, 2016; Lüsebrink et al., 2021; Lüsebrink et al., 2017), there has not yet been a quantitative $\mathrm{T}_{1}$ dataset together with $\mathrm{T}_{2}{ }^{*}$ at mesoscopic resolution in the living human brain.

We plot single-subject $T_{1}$ measurements across cortical depths for the calcarine sulci and Heschl's gyri in both hemispheres in Figure 9 . We observe a dip of $\mathrm{T}_{1}$ values in middle of the cortical thickness in the calcarine sulci, but a similar dip is not visible for Heschl's gyri. This $\mathrm{T}_{1}$ dip is harder to identify in individual brain images compared to the dip in $T_{2}{ }^{*}$. Looking at the variance of $T_{1}$ across cortical depths in group results (Figure 10), we find that variance does not increase as drastically as in $T_{2}{ }^{*}$ profiles. This suggests that $T_{1}$ is less sensitive to laminar architecture than $T_{2}{ }^{*}$. Looking at the above gray-matter voxels, it can be seen that the variance increases, but less than in the $\mathrm{T}_{2}{ }^{*}$ profiles. This is because vessels show on average similar $\mathrm{T}_{1}$ to gray matter, while CSF has a higher $\mathrm{T}_{1}$ (Zhang et al., 2013).

A comparison between $\mathrm{T}_{1}$ and $\mathrm{T}_{2}{ }^{*}$ images leads to interesting observations (e.g. Figure 3D-E). CSF, arteries, and veins can be considered as the three main tissue types that lie above gray matter. When looking at the $\mathrm{T}_{2}{ }^{*}$ images, vessels can be seen as regions with low $\mathrm{T}_{2}{ }^{*}$ while CSF has very high $\mathrm{T}_{2}{ }^{*}$. In Figure $3 \mathrm{D}-\mathrm{E}$, looking at the low $\mathrm{T}_{2}{ }^{*}$ voxels in $\mathrm{T}_{1}$ images reveal that large ( $>1 \mathrm{~mm}$ diameter) arteries and veins seem to have very different $\mathrm{T}_{1}$ values. This difference might be due to the higher velocity of the blood in the arteries compared to veins affecting proper inversion of the 
bioRxiv preprint doi: https://doi.org/10.1101/2021.11.25.470023; this version posted November 25, 2021. The copyright holder for this preprint (which was not certified by peer review) is the author/funder, who has granted bioRxiv a license to display the preprint in perpetuity. It is made available under aCC-BY-ND 4.0 International license.

Mesoscopic Quantification of Cortical Architecture in the Living Human Brain

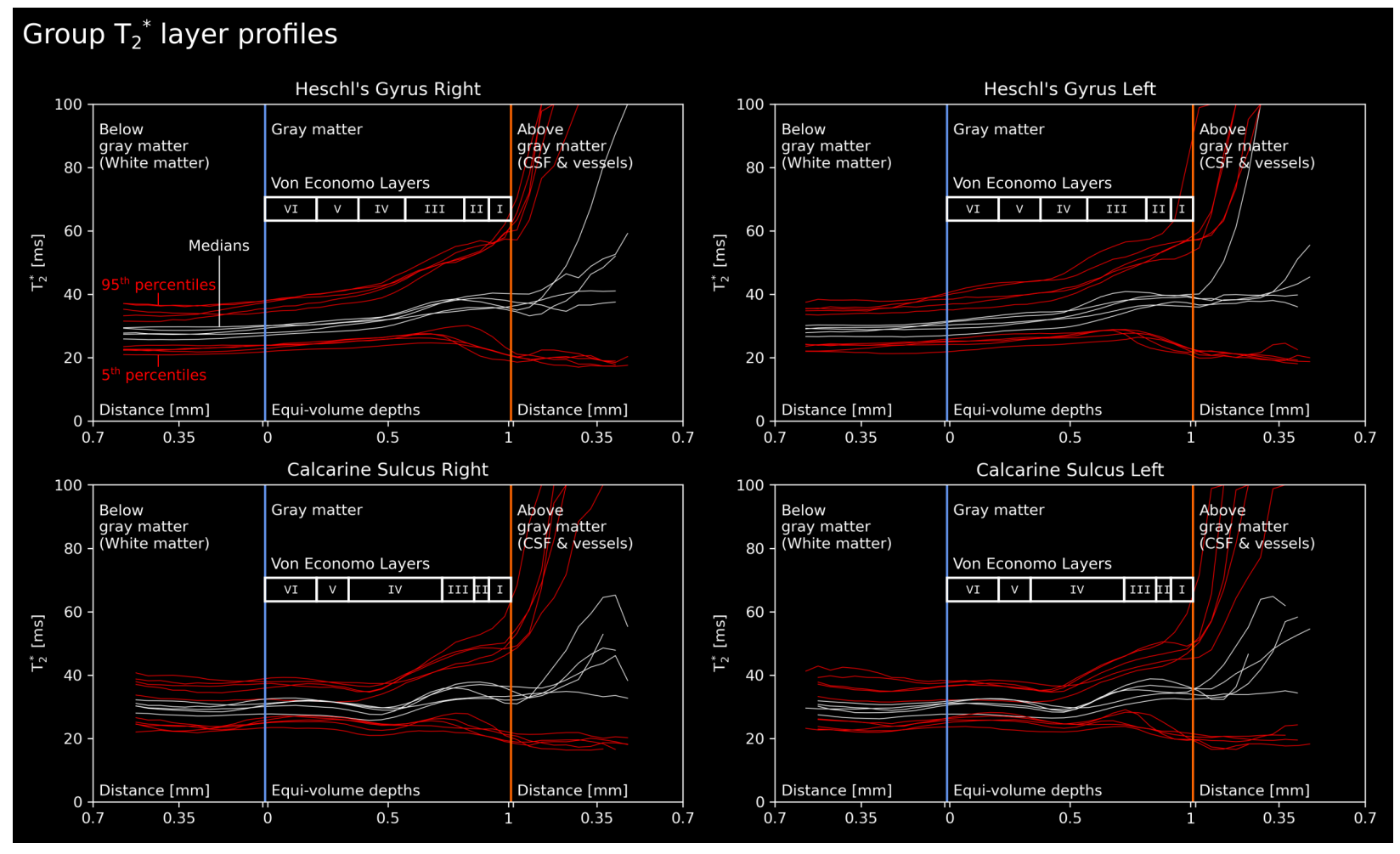

Figure 8: Line plots of $\mathbf{T}_{2}{ }^{*}$ as a function of cortical depth for all five subjects. Format similar to Figure 7 . White lines show the median $\mathrm{T}_{2}{ }^{*}$ calculated for successive bins of cortical depth. Red lines show the $5^{\text {th }} \& 95^{\text {th }}$ percentiles observed for these bins.

arterial signal during MP2RAGE acquisition. However, aside from the arteries, it can be seen that most of the low $\mathrm{T}_{2}{ }^{*}$ voxels above gray matter are not visible in MP2RAGE $T_{1}$ images. This observation is interesting because it shows that $\mathrm{T}_{2}{ }^{*}$ contrast, which is sensitive to macromolecular content and iron, is highly advantageous for localizing veins compared to $\mathrm{T}_{1}$ contrast, which is mostly sensitive to the macromolecular content.

\section{Discussion}

In this study, we have demonstrated acquisition and analysis of high-quality mesoscopic anatomical data from five living human brains. Our primary results include the following: (i) We obtain images of the living human brain at 0.35 $\times 0.35 \times 0.35 \mathrm{~mm}^{3}$ resolution. Our images measure both empirical $\mathrm{T}_{2}{ }^{*}$ and $\mathrm{T}_{1}$ values while covering $1 / 3$ of the brain including the visual and auditory cortices. (ii) In the process of acquiring these data, we reveal a blood motion artifact and develop a simple and effective mitigation method. (iii) To retain fine details in our images, we develop image analysis tools suited for the mesoscopic scale that quantify cortical thickness, cortical curvature, geodesic distances, and are able to parameterize the cortical surface as well as flatten chunks of cortex. (iv) With these tools, we demonstrate mesoscopic cortical substructures of the living human brain such as layers and intracortical vessels, and these are discernible without any statistical analysis. (v) To facilitate future progress in the study of neurobiological structures, we freely share this unique dataset and the associated tools.

\subsection{Mesoscopic Image Analysis Tools}

A major contribution of the present work is the development of mesoscopic image analysis tools. We performed this work because conventional cortical surface analysis tools are inadequate and inconvenient for retaining fine-scale mesoscopic details in our images. Conventional cortical surface processing leverages the triangular mesh data structure (Botsch et al., 2010), which is efficient for representing the cortex as a 2D manifold embedded in 3D. However, this data structure is not optimal for retaining and representing fine-scale image details as it involves resampling the original data defined on a regular grid of voxels onto irregular grid vertices. While creating higher resolution meshes is one 
bioRxiv preprint doi: https://doi.org/10.1101/2021.11.25.470023; this version posted November 25, 2021. The copyright holder for this preprint (which was not certified by peer review) is the author/funder, who has granted bioRxiv a license to display the preprint in perpetuity. It is made available under aCC-BY-ND 4.0 International license.

Mesoscopic Quantification of Cortical Architecture in the Living Human Brain

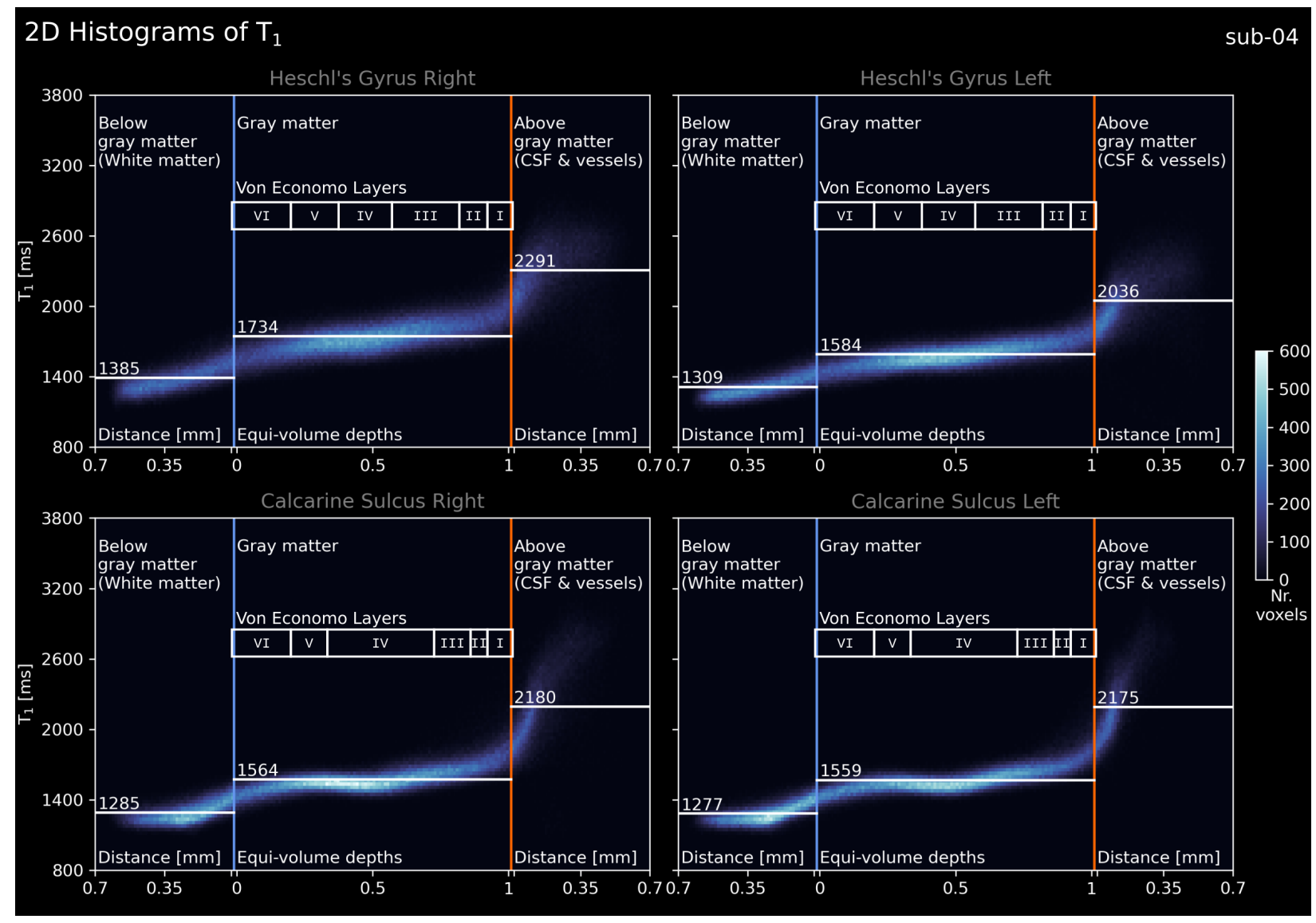

Figure 9: 2D histograms of $T_{1}$ as a function of cortical depth for a single subject (sub-04). The vertical lines show the gray-matter borders: blue for the inner gray-matter border and orange for the outer gray-matter border (see Figure 3D-E). Horizontal white lines show the median $\mathrm{T}_{1}$ for different tissues: below gray matter, gray matter, and above gray matter. See figure supplements showing each individual at https://osf .io/n5bj7 under Supplementary Figures folder.

potential strategy (Kay et al., 2019), this quickly becomes computationally cumbersome. Similar arguments against the triangular meshes are also made by Kemper et al. (2018).

In addition to these issues, the triangular meshes is not well designed for representing the thickness of the cortical surface: the cortical surface is not a 2D sheet but actually a 3D sheet containing varying levels of thickness. We wholesale replace the triangular meshes and associated surface-based analysis algorithms by developing a delayed surface mapping method. That is, we estimate a full continuous mapping between the original brain space (XYZ) and the cortical surface space (UVD) without explicitly committing to a specific mesh representation of the surface. This allows us to create representations and visualizations that refer to the original brain space, thereby allowing the user to avoid or at least delay interpolation until the end. In addition, we can conveniently use the mapping to create flat representations at arbitrarily high resolution, allowing us to not only browse them using standard volume visualization software (e.g. ITK-SNAP, FSLeyes, Brainvoyager), but also to explore the cortical landscape using novel animations (https://osf .io/n5bj7 under Supplementary Figures folder) that leverage the unconnected nature of the rendered elements (point clouds) rather than being constrained by the connected nature of the triangular mesh data structure (Botsch et al., 2010). This adds a whole new toolkit of point-cloud-based volumetric rendering techniques (Berger et al., 2017) to the arsenal of flat cortex visualization techniques. We have implemented our geometric approach within the LayNii software suite (Huber et al., 2021) and have made them publicly available (see Section 5). Our mesoscopic tools can, in principle, be used for any type of voxel-based 3D images, including high resolution fMRI, histology, and lightsheet microscopy images (Amunts et al., 2013; Berman et al., 2021; Hildebrand et al., 2019; Huber et al., 2020). 
bioRxiv preprint doi: https://doi.org/10.1101/2021.11.25.470023; this version posted November 25, 2021. The copyright holder for this preprint (which was not certified by peer review) is the author/funder, who has granted bioRxiv a license to display the preprint in perpetuity. It is made available under aCC-BY-ND 4.0 International license.

Mesoscopic Quantification of Cortical Architecture in the Living Human Brain

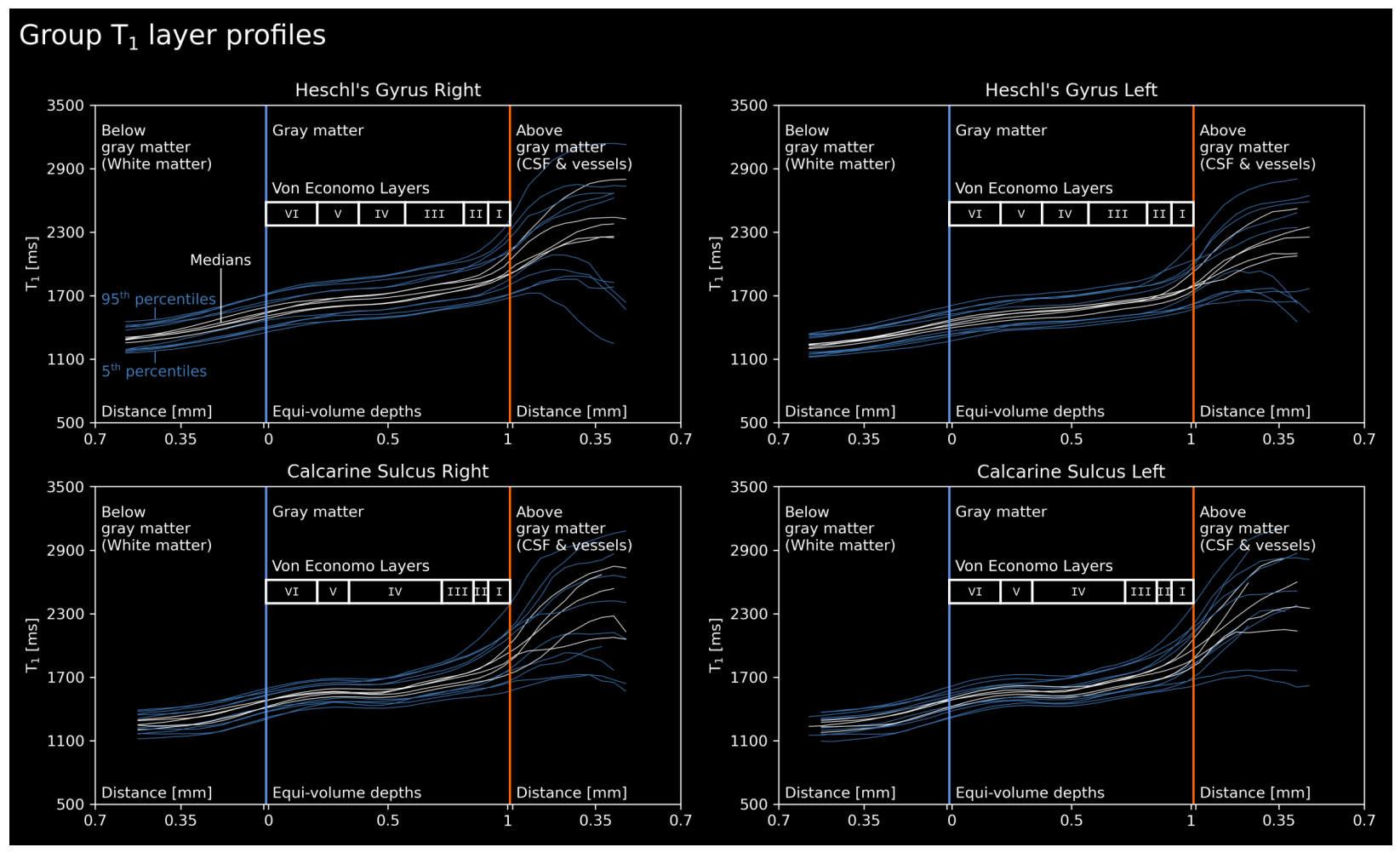

Figure 10: Line plots of $\mathbf{T}_{\mathbf{1}}$ as a function of cortical depth for all five subjects. Format similar to Figure 9 . White lines show the median $T_{1}$ calculated for successive bins of cortical depth. Blue lines show $5^{\text {th }} \& 95^{\text {th }}$ percentiles observed for these bins.

\subsection{Mesoscopic Properties Observed in Visual and Auditory Cortices}

Our mesoscopic images reveal clear cortical substructures. Two main types of cortical substructures are visible: layers and vessels. With regards to the cortical layers, there appears to be a substantial difference between the visual and auditory cortices. In the visual cortex, a distinct layer around the middle gray-matter depth is clearly visible as has been previously shown with in vivo MRI at mesoscopic resolutions (Barbier et al., 2002; Budde et al., 2011; Duyn et al., 2007; Federau \& Gallichan, 2016; Fukunaga et al., 2010; Kemper et al., 2018; Lüsebrink et al., 2021; Zwanenburg et al., 2011). This structure is likely the stria of Gennari (Fulton, 1937; Gennari, 1782; Glickstein \& Rizzolatti, 1984). On the other hand, in our auditory cortex images, a equally distinct layering was not immediately visible, consistent with post-mortem imaging studies (Wallace et al., 2016; Wallace et al., 2002) and previous sub-millimeter attempts to identify layers within the auditory cortex (De Martino et al., 2015; Dick et al., 2012; Dick et al., 2017; Wasserthal et al., 2014). The difference between the visual cortex layers and the auditory cortex layers in $T_{2}{ }^{*}$ and $T_{1}$ images highlight how unique the visual cortex layering is compared to the rest of the cortex. However, as argued within (Wallace et al., 2016), mesoscopic in vivo imaging may still be insufficient to capture the subtle changes in myeloarchitecture aside from primary visual cortex where the stria of Gennari is extremely thick.

Our $\mathrm{T}_{2}{ }^{*}$ images show clear presence of vascular substructures within the cortex. This is interesting because seminal neuroscience works highlight laminar cytoarchitecture, myeloarchitecture, and fiber architecture (Turner, 2013a, 2013b), but rarely mention laminar angioarchitecture. It has been shown that the angioarchitecture of the cortex exhibits a laminar arrangement both across depths and over the cortical surface (Duvernoy et al., 1981; Pfeifer, 1940). Specifically within Duvernoy's work, 4 angioarchitectural layers are postulated. When angioarchitecture layer 1 and 2 are combined, it can be seen that these 4 layers almost equally divide the human cortex. Given that $\mathrm{T}_{2}{ }^{*}$ contrast has a substantial contribution from the presence of blood, the laminar patterns we are observing within the visual cortex (see Figure $3 \mathbf{E}$ ) may also reflect laminar angioarchitecture. Indeed, Pfeifer (1940) showed increased density of blood vessels in middle cortical layers, which might be the origin of the $\mathrm{T}_{2}{ }^{*}$ dip we have observed. More broadly, what constitutes the living brain might be biased by the post-mortem focus within the last century where angioarchitectonic layering within the cortex is largely ignored due to the draining of blood and degradation of blood vessels during fixation and embedding processes. We invite others to make use of our mesoscopic dataset to further study cortical angioarchitecture. 


\subsection{Challenges That Remain for Mesoscopic Imaging}

While we believe we have made substantial progress for mesoscopic MRI, there are several remaining challenges. The most obvious challenge of in vivo mesoscopic MRI is head motion (Jezzard \& Clare, 1999; Zaitsev et al., 2015). In our study, all participants were highly experienced for being scanned and were able to keep their heads relatively still within the data acquisition periods. In addition, we used 3D acquisition sequences rather than 2D sequences; in 3D sequences, within-run head motion is more forgiving. Another advantage of 3D sequences is that they generally enable higher resolution and SNR (Poser et al., 2010; Stirnberg et al., 2017). As a result of using 3D acquisitions and experienced participants, we achieved highly detailed images of cortical substructures, even those as small as intracortical vessels. This result shows that mesoscopic MRI is practical when head motion is minimized and when using 3D acquisition sequences with sufficient SNR. However, for general application, it would be critical to use systems to minimize head motion for less experienced participants, such as prospective motion correction (Lüsebrink et al., 2021; Lüsebrink et al., 2017; Maclaren et al., 2012; Zaitsev et al., 2017), 3D printed head casts (Power et al., 2019), and field monitoring (Barmet et al., 2008). We think that more advanced head motion minimization methods have potential to yield crisper mesoscopic images and broaden the application of mesoscopic MRI to a larger audience.

Even in an ideal case of no head motion, in vivo MRI presents a unique challenge, namely, effects due to the motion of blood. Especially within large arteries, blood reaches very high speeds (Rahman Rasyada \& Azhim, 2018). Such moving blood is known to cause imaging artifacts (Larson et al., 1990; Wehrli, 1990), especially when the time between the phase-encoding and readout (frequency encoding) stages of the MRI signal acquisition gets longer. An obvious case where blood motion artifacts are visible is multi-echo acquisition, where each phase-encoded line of k-space is measured using several successive readouts to acquire multiple echos. Our MEGRE images have captured this artifact in unprecedented detail (Figure 2). Importantly, this artifact is not specific to our anatomical multi-echo acquisition. Any MRI sequence that has long ( $>4 \mathrm{~ms}$ ) time difference between the phase-encoding and readout stages is bound to have this artifact, given that the arterial signal is not effectively nulled. Especially in echo planar imaging (EPI) readouts (Bernstein et al., 2004) commonly used for fMRI, where the image is acquired within very long readout durations (e.g. $>30 \mathrm{~ms}$ ), this blood motion artifact will strongly exhibit itself. Fortunately, the blood motion artifact is limited to regions near large arteries ( $>1 \mathrm{~mm}$ diameter). However, studies that rely on accurate and precise quantification of the brain tissue (e.g. see literature within Mancini et al., 2020), such as multi-parametric mapping and in vivo histology (Edwards et al., 2018) should be aware of this artifact. In addition, studies that rely on weighted contrasts, such as $\mathrm{T}_{2}{ }^{*}$-weighted, should be cautious of this artifact because the arterial signal can be smeared towards the gray matter, causing artifactually hyperintense regions. Moreover, the artifact may corrupt contrast locally by introducing dark regions in the actual position of an artery as its signal is displaced away from its trunk. This can cause arteries to appear similar to the venous signal in $\mathrm{T}_{2}{ }^{*}$-weighted images. Thus, dark regions in $\mathrm{T}_{2}{ }^{*}$-weighted images - especially near the pial surface - cannot be conclusively labelled as veins, as has been suggested (Kay et al., 2019; Moerel et al., 2018; Olman et al., 2007).

In our study, we used conservative amounts of image acquisition acceleration (see Table 1). This resulted in somewhat lengthy but still feasible anatomical acquisition durations (10-14 min). The choice of minimal acceleration was deliberate in order to minimize artifacts, maximize SNR, and thereby establish a benchmark dataset. However, a persistent challenge for mesoscopic imaging is long data acquisition times. Faster acquisitions are especially needed for clinical populations. From a methods development perspective, our fully sampled high-resolution multi-echo dataset might be useful for efforts in which a dataset is subsampled and methods are developed to optimally recover the full dataset from limited data, such as parallel imaging or model based reconstructions (Ye, 2019).

\subsection{Future Neuroscience Applications for Mesoscopic MRI}

Our study suggests exciting possibilities for mesoscopic imaging. From a clinical perspective, mesoscopic in vivo imaging of human cortical architecture creates the opportunity to develop a novel set of biomarkers for the healthy development of adult cortical laminar structure and its disruption in neurological and psychiatric disorders (McColgan et al., 2021). Prime candidate conditions for mesoscopic imaging include well-established but subtle abnormalities in laminar structure that currently lack clear imaging correlates such as layer-specific neuronal loss in amyotrophic lateral sclerosis (Braak et al., 2017) and Huntington's disease (Rüb et al., 2016), as well as developmental disruption of cortical layering in focal cortical dysplasia (Blümcke et al., 2011). From a cortical parcellation perspective, future analyses may investigate whether inter-regional variability in laminar structure can be leveraged for parcellating cortical areas using approaches like those used for cytoarchitectonic data (Gulban et al., 2020; Morosan et al., 2001; Schleicher et al., 1999; Zachlod et al., 2020). With additional acquisition time, it is clear that mesoscopic coverage of $1 / 3$ of the brain can be easily increased to include the whole brain by scanning different slabs and stitching them together. From an fMRI perspective, imaging the angioarchitectonic substructure of the cortex is necessary for building biophysical models of the fMRI signal (Akbari et al., 2021; Báez-Yánez et al., 2020; Cheng et al., 2019; Havlicek \& Uludag, 2020; Polimeni 
\& Lewis, 2021). The spatial variability of fMRI signals due to mesoscopic angioarchitecture is not well understood. The effect of intracortical veins has been the focus of fMRI signal modelling so far (Havlicek \& Uludag, 2020; Heinzle et al., 2016; Markuerkiaga et al., 2016; Markuerkiaga et al., 2021; Uludag et al., 2009), although empirical studies have shown considerable contributions from pial veins (Bause et al., 2020; Olman et al., 2007; Turner, 2002; Winawer et al., 2010). Further, several sub-millimeter fMRI studies have found heterogenous response profiles across cortical depths (Chen et al., 2013; Fracasso et al., 2018; Kashyap et al., 2018). Thus, the angioarchitecture information in our mesoscopic images might help extend classical models of fMRI signals to consider the heterogeneity of the underlying vasculature and improve the interpretability of laminar BOLD fMRI profiles.

\section{Data and Code Availability Statement}

Unprocessed data, sequence (MP2RAGE and MEGRE) parameters PDFs, and part of the processed data (due to data storage constraints) used in this study are available at: https://osf.io/n5bj7// under Data folder. Geometric analysis algorithms developed for this study (LN2_MULTILATERATE and LN2_PATCH_LATTEN) implemented in C++ within LayNii software suite v2.2.0 are available at: https://github.com/layerfMRI/LayNii. Data processing pipelines used in this study are available at: https://github.com/ofgulban/meso-MRI.

\section{Author Contributions}

According to the CRediT system (https://casrai.org/credit/)

Conceptualization: O.F.G., D.I.

Data curation: O.F.G., D.I.

Formal Analysis: O.F.G.

Funding acquisition: D.I., R.G.

Investigation: O.F.G., D.I.

Methodology: O.F.G., D.I., K.K., S.B., R.H.

Project administration: O.F.G., D.I., K.K.

Resources: O.F.G., R.G., R.H., B.A.P.

Software: O.F.G., R.H.

Supervision: O.F.G., D.I., K.K.

Validation: O.F.G., D.I., K.W., S.B.

Visualization: O.F.G., K.K., D.I.

Writing - original draft: O.F.G., D.I., K.K.

Writing - review \& editing: O.F.G., D.I., K.K., S.B., K.W., R.H., B.A.P., R.G.

\section{Acknowledgements}

We thank Federico De Martino for his contributions in the early stages of this study. We thank Valentin Kemper, Martin Havlicek, Kamil Uludag, Nikolaus Weiskopf, Logan Dowdle, Jonathan Winawer, Simon Robinson, Korbinian Eckstein, and Michelle Moerel for discussions and comments at various stages. This study was approved by the local ethics committee. SB was funded from the NHMRC-NIH BRAIN Initiative Collaborative Research Grant APP1117020, and NIH grant 1R01MH111419. R.H. was funded from the NWO VENI project 016.Veni.198.032. K.W. was funded by the Wellcome Trust (215901/Z/19/Z). B.P. was partially funded by the NWO VIDI grant 16.Vidi.178.052, by the National Institute for Health grant R01MH/111444 (PI: David Feinberg) and by the H2020 FET-Open AROMA grant agreement no. 88587. R.G. received funding from the European Union's Horizon 2020 Framework Programme for Research and Innovation under the Specific Grant Agreement No. 945539 (Human Brain Project SGA3). O.F.G. and R.G. have financial interest tied to Brain Innovation. Scanning was supported by FPN (faculty of psychology and neuroscience) via the MBIC grant scheme. Scanning was performed at the facilities of Scannexus B.V. (Maastricht, Netherlands). $\mathrm{T}_{2}{ }^{*}$-mapping was done with an ASPIRE sequence, kindly provided by Simon Robinson via SIEMENS C2P.

\section{References}

Akbari, A., Bollmann, S., Ali, T. S., \& Barth, M. (2021). Modelling the depth-dependent VASO and BOLD responses in human primary visual cortex. bioRxiv, 1-31. 
Allen, E. J., St-Yves, G., Wu, Y., Breedlove, J. L., Dowdle, L. T., Caron, B., Pestilli, F., Charest, I., Hutchinson, J. B., Naselaris, T., \& Kay, K. (2021). A massive 7T fMRI dataset to bridge cognitive and computational neuroscience. bioRxiv, 2021.02.22.432340.

Amunts, K., Lepage, C., Borgeat, L., Mohlberg, H., Dickscheid, T., Rousseau, M.-E., Bludau, S., Bazin, P.-L., Lewis, L. B., Oros-Peusquens, A.-M., Shah, N. J., Lippert, T., Zilles, K., \& Evans, A. C. (2013). BigBrain: an ultrahigh-resolution 3D human brain model. Science (New York, N.Y.), 340(6139), 1472-5. https://doi.org/10. 1126/science. 1235381

Báez-Yánez, M. G., Siero, J. C., \& Petridou, N. (2020). A statistical 3D model of the human cortical vasculature to compute the hemodynamic fingerprint of the BOLD fMRI signal. bioRxiv, 31(0), 1-63.

Barbier, E. L., Marrett, S., Danek, A., Vortmeyer, A., Van Gelderen, P., Duyn, J., Bandettini, P., Grafman, J., \& Koretsky, A. P. (2002). Imaging cortical anatomy by high-resolution MR at 3.0T: Detection of the stripe of Gennari in visual area 17. Magnetic Resonance in Medicine, 48(4), 735-738. https://doi.org/10.1002/mrm.10255

Barmet, C., De Zanche, N., \& Pruessmann, K. P. (2008). Spatiotemporal magnetic field monitoring for MR. Magnetic Resonance in Medicine, 60(1), 187-197. https://doi.org/10.1002/mrm.21603

Bause, J., Polimeni, J. R., Stelzer, J., In, M. H., Ehses, P., Kraemer-Fernandez, P., Aghaeifar, A., Lacosse, E., Pohmann, R., \& Scheffler, K. (2020). Impact of prospective motion correction, distortion correction methods and large vein bias on the spatial accuracy of cortical laminar fMRI at 9.4 Tesla. NeuroImage, 208(April 2019). https://doi.org/10.1016/j.neuroimage.2019.116434

Bentivoglio, M., \& Mazzarello, P. (2009). Chapter 12 The anatomical foundations of clinical neurology. Handbook of clinical neurology (pp. 149-168). Elsevier. https://doi.org/10.1016/S0072-9752(08)02112-X

Berger, M., Tagliasacchi, A., Seversky, L. M., Alliez, P., Guennebaud, G., Levine, J. A., Sharf, A., \& Silva, C. T. (2017). A Survey of Surface Reconstruction from Point Clouds (J. Chen, Ed.). Computer Graphics Forum, 36(1), 301-329. https://doi.org/10.1111/cgf.12802

Berman, A. J., Grissom, W. A., Witzel, T., Nasr, S., Park, D. J., Setsompop, K., \& Polimeni, J. R. (2021). Ultra-high spatial resolution BOLD fMRI in humans using combined segmented-accelerated VFA-FLEET with a recursive RF pulse design. Magnetic Resonance in Medicine, 85(1), 120-139. https://doi.org/10.1002/mrm.28415

Bernier, M., Cunnane, S. C., \& Whittingstall, K. (2018). The morphology of the human cerebrovascular system. Human Brain Mapping, 39(12), 4962-4975. https://doi.org/10.1002/hbm.24337

Bernstein, M. A., King, K. F., \& Zhou, X. J. (2004). Handbook of MRI Pulse Sequences. Elsevier. https://doi.org/10. 1016/B978-0-12-092861-3.X5000-6

Blümcke, I., Thom, M., Aronica, E., Armstrong, D. D., Vinters, H. V., Palmini, A., Jacques, T. S., Avanzini, G., Barkovich, A. J., Battaglia, G., Becker, A., Cepeda, C., Cendes, F., Colombo, N., Crino, P., Cross, J. H., Delalande, O., Dubeau, F., Duncan, J., ... Spreafico, R. (2011). The clinicopathologic spectrum of focal cortical dysplasias: a consensus classification proposed by an ad hoc Task Force of the ILAE Diagnostic Methods Commission. Epilepsia, 52(1), 158-74. https://doi.org/10.1111/j.1528-1167.2010.02777.x

Bok, S. T. (1959). Histonomy of the Cerebral Cortex. Elsevier.

Botsch, M., Kobbelt, L., Pauly, M., Alliez, P., \& Levy, B. (2010). Polygon Mesh Processing. CRC press. https : //doi.org/10.1201/b10688

Braak, H., Ludolph, A. C., Neumann, M., Ravits, J., \& Del Tredici, K. (2017). Pathological TDP-43 changes in Betz cells differ from those in bulbar and spinal $\alpha$-motoneurons in sporadic amyotrophic lateral sclerosis. Acta neuropathologica, 133(1), 79-90. https://doi.org/10.1007/s00401-016-1633-2

Brett, M., Hanke, M., Côté, M.-A., Markiewicz, C., Ghosh, S., Wassermann, D., Gerhard, S., Larson, E., Lee, G. R., Halchenko, Y., Kastman, E., M, C., Morency, F. C., Maloney, B., Rokem, A., Cottaar, M., Millman, J., Jaeilepp, Gramfort, A., ... Nimmo-Smith, I. (2017). Nipy/nibabel: 2.2.0. https://doi.org/10.5281/zenodo.1011207

Brinkmann, R. (2008). The Art and Science of Digital Compositing. Elsevier. https://doi.org/10.1016/B978-0-12370638-6.X0001-6

Budde, J., Shajan, G., Hoffmann, J., Uğurbil, K., \& Pohmann, R. (2011). Human imaging at 9.4 T using T2*, phase-, and susceptibility-weighted contrast. Magnetic Resonance in Medicine, 65(2), 544-550. https : //doi.org/10.1002/mrm.22632

Chen, H., Zhang, T., Guo, L., Li, K., Yu, X., Li, L., Hu, X., Han, J., Hu, X., \& Liu, T. (2013). Coevolution of gyral folding and structural connection patterns in primate brains. Cerebral cortex (New York, N.Y. : 1991), 23(5), 1208-17. https://doi.org/10.1093/cercor/bhs113

Cheng, X., Berman, A. J., Polimeni, J. R., Buxton, R. B., Gagnon, L., Devor, A., Sakadžić, S., \& Boas, D. A. (2019). Dependence of the MR signal on the magnetic susceptibility of blood studied with models based on real microvascular networks. Magnetic Resonance in Medicine, 81(6), 3865-3874. https://doi.org/10.1002/mrm. 27660

Cohen-Adad, J. (2014). What can we learn from T2* maps of the cortex? NeuroImage, 93 Pt 2, 189-200. https: //doi.org/10.1016/j.neuroimage.2013.01.023 
Cohen-Adad, J., Polimeni, J. R., Helmer, K. G., Benner, T., McNab, J. A., Wald, L. L., Rosen, B. R., \& Mainero, C. (2012). T $2 *$ mapping and B 0 orientation-dependence at 7T reveal cyto- and myeloarchitecture organization of the human cortex. NeuroImage, 60(2), 1006-1014. https://doi.org/10.1016/j.neuroimage.2012.01.053

De Martino, F., Moerel, M., Xu, J., van de Moortele, P.-F., Ugurbil, K., Goebel, R., Yacoub, E., \& Formisano, E. (2015). High-Resolution Mapping of Myeloarchitecture In Vivo: Localization of Auditory Areas in the Human Brain. Cerebral cortex (New York, N.Y. : 1991), 25(10), 3394-405. https://doi.org/10.1093/cercor/bhu150

Deistung, A., Schäfer, A., Schweser, F., Biedermann, U., Turner, R., \& Reichenbach, J. R. (2013). Toward in vivo histology: a comparison of quantitative susceptibility mapping (QSM) with magnitude-, phase-, and R2*imaging at ultra-high magnetic field strength. NeuroImage, 65, 299-314. https://doi.org/10.1016/j.neuroimage. 2012.09.055

Quantitative susceptibility mapping at ultra high field. It seems that this mapping is good for subcortical segmentations.

Dick, F., Tierney, A. T., Lutti, A., Josephs, O., Sereno, M. I., \& Weiskopf, N. (2012). In vivo functional and myeloarchitectonic mapping of human primary auditory areas. The Journal of neuroscience : the official journal of the Society for Neuroscience, 32(46), 16095-105. https://doi.org/10.1523/JNEUROSCI.1712-12.2012

Dick, F. K., Lehet, M. I., Callaghan, M. F., Keller, T. A., Sereno, M. I., \& Holt, L. L. (2017). Extensive Tonotopic Mapping across Auditory Cortex Is Recapitulated by Spectrally Directed Attention and Systematically Related to Cortical Myeloarchitecture. The Journal of neuroscience : the official journal of the Society for Neuroscience, 37(50), 12187-12201. https://doi.org/10.1523/JNEUROSCI.1436-17.2017

Duvernoy, H. M., Delon, S., \& Vannson, J. L. (1981). Cortical blood vessels of the human brain. Brain research bulletin, 7(5), 519-79. https://doi.org/10.1016/0361-9230(81)90007-1

Duyn, J. H., van Gelderen, P., Li, T.-Q., de Zwart, J. A., Koretsky, A. P., \& Fukunaga, M. (2007). High-field MRI of brain cortical substructure based on signal phase. Proceedings of the National Academy of Sciences, 104(28), 11796-11801. https://doi.org/10.1073/pnas.0610821104

Eckstein, K., Dymerska, B., Bachrata, B., Bogner, W., Poljanc, K., Trattnig, S., \& Robinson, S. D. (2018). Computationally Efficient Combination of Multi-channel Phase Data From Multi-echo Acquisitions (ASPIRE). Magnetic resonance in medicine, 79(6), 2996-3006. https://doi.org/10.1002/mrm.26963

Edwards, L. J., Kirilina, E., Mohammadi, S., \& Weiskopf, N. (2018). Microstructural imaging of human neocortex in vivo. NeuroImage, 182, 184-206. https://doi.org/10.1016/j.neuroimage.2018.02.055

Federau, C., \& Gallichan, D. (2016). Motion-correction enabled ultra-high resolution in-vivo 7T-MRI of the brain. PLoS ONE, 11(5), 1-12. https://doi.org/10.1371/journal.pone.0154974

Finger, S., Boller, F., \& Tyler, K. (2009). Handbook of Clinical Neurology HIstory of Neurology (Vol. 95). Elsevier.

Fischl, B., Sereno, M. I., \& Dale, A. M. (1999). Cortical surface-based analysis: II. Inflation, flattening, and a surfacebased coordinate system. NeuroImage, 9(2), 195-207. https://doi.org/10.1006/nimg.1998.0396

Fischl, B., Sereno, M. I., Tootell, R. B., \& Dale, A. M. (1999). High-resolution intersubject averaging and a coordinate system for the cortical surface. Human Brain Mapping, 8(4), 272-284. https://doi.org/10.1002/(SICI)10970193(1999)8:4<272::AID-HBM10>3.0.CO;2-4

Fracasso, A., Luijten, P. R., Dumoulin, S. O., \& Petridou, N. (2018). Laminar imaging of positive and negative BOLD in human visual cortex at 7 T. NeuroImage, 164(February 2017), 100-111. https://doi.org/10.1016/j.neuroimage. 2017.02.038

Fukunaga, M., Li, T. Q., Van Gelderen, P., De Zwart, J. A., Shmueli, K., Yao, B., Lee, J., Maric, D., Aronova, M. A., Zhang, G., Leapman, R. D., Schenck, J. F., Merkle, H., \& Duyn, J. H. (2010). Layer-specific variation of iron content in cerebral cortex as a source of MRI contrast. Proceedings of the National Academy of Sciences of the United States of America, 107(8), 3834-3839. https://doi.org/10.1073/pnas.0911177107

Fulton, J. F. (1937). A Note on Francesco Gennari and the Early History of Cytoarchitectural Studies of the Cerebral Cortex. Bulletin of the Institute of the History of Medicine, 5(10), 895-913.

Gennari, F. (1782). De Peculiari Structura Cerebri. Nonnullisque ejus morbis. Ex Regio Typographeo, Parma., 44(0).

Geyer, S. (2013). Microstructural Parcellation of the Human Cerebral Cortex (S. Geyer \& R. Turner, Eds.). Springer Berlin Heidelberg. https://doi.org/10.1007/978-3-662-45766-5

Glickstein, M., \& Rizzolatti, G. (1984). Francesco Gennari and the structure of the cerebral cortex. Trends in Neurosciences, 7(12), 464-467. https://doi.org/10.1016/S0166-2236(84)80255-6

Gulban, O. F., Goebel, R., Moerel, M., Zachlod, D., Mohlberg, H., Amunts, K., \& De Martino, F. (2020). Improving a probabilistic cytoarchitectonic atlas of auditory cortex using a novel method for inter-individual alignment. eLife, 9, 1-29. https://doi.org/10.7554/eLife.56963

Gulban, O. F., Schneider, M., Marquardt, I., Haast, R. A. M., \& De Martino, F. (2018). A scalable method to improve gray matter segmentation at ultra high field MRI. PloS one, 13(6), e0198335. https://doi.org/10.1371/journal. pone.0198335 
bioRxiv preprint doi: https://doi.org/10.1101/2021.11.25.470023; this version posted November 25,2021 . The copyright holder for this preprint (which was not certified by peer review) is the author/funder, who has granted bioRxiv a license to display the preprint in perpetuity. It is made available under aCC-BY-ND 4.0 International license.

Mesoscopic Quantification of Cortical Architecture in the Living Human Brain

Haast, R. A. M., Ivanov, D., Formisano, E., \& Uludağ, K. (2016). Reproducibility and Reliability of Quantitative and Weighted T1 and T2* Mapping for Myelin-Based Cortical Parcellation at 7 Tesla. Frontiers in neuroanatomy, 10(NOV), 112. https://doi.org/10.3389/fnana.2016.00112

Havlicek, M., \& Uludag, K. (2020). A dynamical model of the laminar BOLD response. NeuroImage, 116209. https://doi.org/10.1016/j.neuroimage.2019.116209

Heinzle, J., Koopmans, P. J., den Ouden, H. E. M., Raman, S., \& Stephan, K. E. (2016). A hemodynamic model for layered BOLD signals. NeuroImage, 125, 556-570. https://doi.org/10.1016/j.neuroimage.2015.10.025

Hildebrand, S., Schueth, A., Herrler, A., Galuske, R., \& Roebroeck, A. (2019). Scalable Labeling for Cytoarchitectonic Characterization of Large Optically Cleared Human Neocortex Samples. Scientific Reports, 9(1), 1-11. https://doi.org/10.1038/s41598-019-47336-9

Huber, L., Finn, E. S., Chai, Y., Goebel, R., Stirnberg, R., Stöcker, T., Marrett, S., Uludag, K., Kim, S. G., Han, S. H., Bandettini, P. A., \& Poser, B. A. (2020). Layer-dependent functional connectivity methods. Progress in Neurobiology, (March). https://doi.org/10.1016/j.pneurobio.2020.101835

Huber, L., Handwerker, D. A., Jangraw, D. C., Chen, G., Hall, A., Stüber, C., Gonzalez-Castillo, J., Ivanov, D., Marrett, S., Guidi, M., Goense, J., Poser, B. A., \& Bandettini, P. A. (2017). High-Resolution CBV-fMRI Allows Mapping of Laminar Activity and Connectivity of Cortical Input and Output in Human M1. Neuron, 96(6), 1253-1263.e7. https://doi.org/10.1016/j.neuron.2017.11.005

Huber, L. ( (, Poser, B. A., Bandettini, P. A., Arora, K., Wagstyl, K., Cho, S., Goense, J., Nothnagel, N., Morgan, A. T., van den Hurk, J., Müller, A. K., Reynolds, R. C., Glen, D. R., Goebel, R., \& Gulban, O. F. (2021). LayNii: A software suite for layer-fMRI. NeuroImage, 237, 118091. https://doi.org/10.1016/j.neuroimage.2021.118091

Huck, J., Wanner, Y., Fan, A. P., Jäger, A. T., Grahl, S., Schneider, U., Villringer, A., Steele, C. J., Tardif, C. L., Bazin, P. L., \& Gauthier, C. J. (2019). High resolution atlas of the venous brain vasculature from 7 T quantitative susceptibility maps. Brain Structure and Function, 224(7), 2467-2485. https://doi.org/10.1007/s00429-01901919-4

Hunter, J. D. (2007). Matplotlib: A 2D graphics environment. Computing In Science \& Engineering, 9(3), 90-95. https://doi.org/10.1109/MCSE.2007.55

Jezzard, P., \& Clare, S. (1999). Sources of distortion in functional MRI data. Human Brain Mapping, 8(2-3), 80-85. https://doi.org/10.1002/(SICI)1097-0193(1999)8:2/3<80::AID-HBM2>3.0.CO;2-C

Jones, E., Oliphant, T., Peterson, P., et al. (2001). \{SciPy\}: Open source scientific tools for $\{$ Python $\}$ [Online; accessed 2015-07-13].

Kashyap, S., Ivanov, D., Havlicek, M., Poser, B. A., \& Uludag, K. (2018). Impact of acquisition and analysis strategies on cortical depth-dependent fMRI. NeuroImage, 168, 332-344. https://doi.org/10.1016/j.neuroimage.2017.05.022

Kay, K., Jamison, K. W., Vizioli, L., Zhang, R., Margalit, E., \& Ugurbil, K. (2019). A critical assessment of data quality and venous effects in sub-millimeter fMRI. NeuroImage, 189(February), 847-869. https://doi.org/10.1016/j. neuroimage.2019.02.006

Kemper, V. G., De Martino, F., Emmerling, T. C., Yacoub, E., \& Goebel, R. (2018). High resolution data analysis strategies for mesoscale human functional MRI at 7 and 9.4 T. NeuroImage, 164(March), 48-58. https: //doi.org/10.1016/j.neuroimage.2017.03.058

Kirilina, E., Helbling, S., Morawski, M., Pine, K., Reimann, K., Jankuhn, S., Dinse, J., Deistung, A., Reichenbach, J. R., Trampel, R., Geyer, S., Müller, L., Jakubowski, N., Arendt, T., Bazin, P.-L., \& Weiskopf, N. (2020). Superficial white matter imaging: Contrast mechanisms and whole-brain in vivo mapping. Science Advances, 6(41), eaaz9281.

Kleinnijenhuis, M. (2014). Imaging fibres in the brain. https://doi.org/10.13140/2.1.4788.7689

Larson, T. C., Kelly, W. M., Ehman, R. L., \& Wehrli, F. W. (1990). Spatial misregistration of vascular flow during MR imaging of the CNS: cause and clinical significance. AJR. American journal of roentgenology, 155(5), 1117-24. https://doi.org/10.2214/ajr.155.5.2120946

Lüsebrink, F., Mattern, H., Yakupov, R., Acosta-Cabronero, J., Ashtarayeh, M., Oeltze-Jafra, S., \& Speck, O. (2021). Comprehensive ultrahigh resolution whole brain in vivo MRI dataset as a human phantom. Scientific Data, 8(1), 1-14. https://doi.org/10.1038/s41597-021-00923-w

Lüsebrink, F., Sciarra, A., Mattern, H., Yakupov, R., \& Speck, O. (2017). T1-weighted in vivo human whole brain MRI dataset with an ultrahigh isotropic resolution of $250 \mu \mathrm{m}$. Scientific data, 4, 170032. https://doi.org/10.1038/ sdata. 2017.32

Maclaren, J., Armstrong, B. S., Barrows, R. T., Danishad, K. A., Ernst, T., Foster, C. L., Gumus, K., Herbst, M., Kadashevich, I. Y., Kusik, T. P., Li, Q., Lovell-Smith, C., Prieto, T., Schulze, P., Speck, O., Stucht, D., \& Zaitsev, M. (2012). Measurement and Correction of Microscopic Head Motion during Magnetic Resonance Imaging of the Brain. PLoS ONE, 7(11), 3-11. https://doi.org/10.1371/journal.pone.0048088

Mancini, M., Karakuzu, A., Cohen-Adad, J., Cercignani, M., Nichols, T. E., \& Stikov, N. (2020). An interactive meta-analysis of MRI biomarkers of Myelin. eLife, 9, 1-23. https://doi.org/10.7554/eLife.61523 
bioRxiv preprint doi: https://doi.org/10.1101/2021.11.25.470023; this version posted November 25,2021 . The copyright holder for this preprint (which was not certified by peer review) is the author/funder, who has granted bioRxiv a license to display the preprint in perpetuity. It is made available under aCC-BY-ND 4.0 International license.

Mesoscopic Quantification of Cortical Architecture in the Living Human Brain

Markuerkiaga, I., Barth, M., \& Norris, D. G. (2016). A cortical vascular model for examining the specificity of the laminar BOLD signal. NeuroImage, 132, 491-498. https://doi.org/10.1016/j.neuroimage.2016.02.073

Markuerkiaga, I., Marques, J. P., Bains, L. J., \& Norris, D. G. (2021). An in-vivo study of BOLD laminar responses as a function of echo time and static magnetic field strength. Scientific Reports, 11(1), 1-13. https://doi.org/10. 1038/s41598-021-81249-w

Marques, J. P., Khabipova, D., \& Gruetter, R. (2017). Studying cyto and myeloarchitecture of the human cortex at ultra-high field with quantitative imaging: R1, R2* and magnetic susceptibility. NeuroImage, 147(December 2016), 152-163. https://doi.org/10.1016/j.neuroimage.2016.12.009

Marques, J. P., Kober, T., Krueger, G., van der Zwaag, W., de Moortele, P.-F., \& Gruetter, R. (2010). MP2RAGE, a self bias-field corrected sequence for improved segmentation and T1-mapping at high field. NeuroImage, 49(2), 1271-1281. https://doi.org/10.1016/j.neuroimage.2009.10.002

McColgan, P., Helbling, S., Vaculčiaková, L., Pine, K., Wagstyl, K., Attar, F. M., Edwards, L., Papoutsi, M., Wei, Y., Van den Heuvel, M. P., Tabrizi, S. J., Rees, G., \& Weiskopf, N. (2021). Relating quantitative 7T MRI across cortical depths to cytoarchitectonics, gene expression and connectomics. Human Brain Mapping, (July), 1-14. https://doi.org/10.1002/hbm.25595

Moerel, M., De Martino, F., Kemper, V. G., Schmitter, S., Vu, A. T., Uğurbil, K., Formisano, E., \& Yacoub, E. (2018). Sensitivity and specificity considerations for fMRI encoding, decoding, and mapping of auditory cortex at ultra-high field. NeuroImage, 164(March 2017), 18-31. https://doi.org/10.1016/j.neuroimage.2017.03.063

Morosan, P., Rademacher, J., Schleicher, A., Amunts, K., Schormann, T., \& Zilles, K. (2001). Human primary auditory cortex: cytoarchitectonic subdivisions and mapping into a spatial reference system. NeuroImage, 13(4), 684701. https://doi.org/10.1006/nimg.2000.0715

Nieuwenhuys, R. (2013). The myeloarchitectonic studies on the human cerebral cortex of the Vogt-Vogt school, and their significance for the interpretation of functional neuroimaging data. Brain structure \& function, 218(2), 303-52. https://doi.org/10.1007/s00429-012-0460-z

Olman, C. A., Inati, S., \& Heeger, D. J. (2007). The effect of large veins on spatial localization with GE BOLD at 3 T: Displacement, not blurring. NeuroImage, 34(3), 1126-1135. https://doi.org/10.1016/j.neuroimage.2006.08.045

Peters, A. M., Brookes, M. J., Hoogenraad, F. G., Gowland, P. A., Francis, S. T., Morris, P. G., \& Bowtell, R. (2007). T2* measurements in human brain at 1.5, 3 and 7 T. Magnetic Resonance Imaging, 25(6), 748-753. https://doi.org/10.1016/j.mri.2007.02.014

Pfeifer, R. A. (1940). Die angioarchitektonische areale gliederung der grosshirnrinde. Georg Thieme.

Polimeni, J. R., \& Lewis, L. D. (2021). Imaging faster neural dynamics with fast fMRI: a need for updated models of the hemodynamic response. Progress in Neurobiology, (October 2020), 102174. https://doi.org/10.1016/j. pneurobio.2021.102174

Poser, B. A., Koopmans, P. J., Witzel, T., Wald, L. L., \& Barth, M. (2010). Three dimensional echo-planar imaging at 7 tesla. NeuroImage, 51(1), 261-266. https://doi.org/10.1016/j.neuroimage.2010.01.108

Power, J. D., Silver, B. M., Silverman, M. R., Ajodan, E. L., Bos, D. J., \& Jones, R. M. (2019). Customized head molds reduce motion during resting state fMRI scans. NeuroImage, 189(October 2018), 141-149. https: //doi.org/10.1016/j.neuroimage.2019.01.016

Rahman Rasyada, A., \& Azhim, A. (2018). Flow Velocity in Common Carotid Artery. Carotid artery - gender and health [working title]. IntechOpen. https://doi.org/10.5772/intechopen.80712

Raichle, M. E. (2009a). A brief history of human brain mapping. Trends in neurosciences, 32(2), 118-26. https: //doi.org/10.1016/j.tins.2008.11.001

Raichle, M. e. (2009b). Chapter 18 The origins of functional brain imaging in humans. Handbook of clinical neurology (pp. 257-268). Elsevier. https://doi.org/10.1016/S0072-9752(08)02118-0

Rüb, U., Seidel, K., Heinsen, H., Vonsattel, J. P., den Dunnen, W. F., \& Korf, H. W. (2016). Huntington's disease (HD): the neuropathology of a multisystem neurodegenerative disorder of the human brain. Brain pathology (Zurich, Switzerland), 26(6), 726-740. https://doi.org/10.1111/bpa.12426

Schleicher, A., Amunts, K., Geyer, S., Morosan, P., \& Zilles, K. (1999). Observer-independent method for microstructural parcellation of cerebral cortex: A quantitative approach to cytoarchitectonics. NeuroImage. https://doi.org/10.1006/nimg.1998.0385

Sethian, J. A. (1996). A fast marching level set method for monotonically advancing fronts. Proceedings of the National Academy of Sciences of the United States of America, 93(4), 1591-5. https://doi.org/10.1073/pnas.93.4.1591

Stahnisch, F. W. (2010). Chapter 11: on the use of animal experimentation in the history of neurology. Handbook of clinical neurology, 95(100), 129-48. https://doi.org/10.1016/S0072-9752(08)02111-8

Stirnberg, R., Huijbers, W., Brenner, D., Poser, B. A., Breteler, M., \& Stöcker, T. (2017). Rapid whole-brain resting-state fMRI at 3 T: Efficiency-optimized three-dimensional EPI versus repetition time-matched simultaneous-multislice EPI. NeuroImage, 163(August), 81-92. https://doi.org/10.1016/j.neuroimage.2017.08.031

Turner, R. (2002). How much codex can a vein drain? Downstream dilution of activation-related cerebral blood oxygenation changes. NeuroImage, 16(4), 1062-1067. https://doi.org/10.1006/nimg.2002.1082 
Turner, R. (2013a). MRI Methods for In-Vivo Cortical Parcellation. In S. Geyer \& R. Turner (Eds.), Microstructural parcellation of the human cerebral cortex (pp. 197-220). Springer. https://doi.org/10.1007/978-3-642-37824-9

Turner, R. (2013b). Where Matters: New Approaches to Brain Analysis. In S. Geyer \& R. Turner (Eds.), Microstructural parcellation of the human cerebral cortex (pp. 179-196). Springer. https://doi.org/10.1007/978-3-642-37824-9

Uludag, K., Müller-Bierl, B., \& Ugurbil, K. (2009). An integrative model for neuronal activity-induced signal changes for gradient and spin echo functional imaging. NeuroImage, 48(1), 150-65. https://doi .org/10.1016/j. neuroimage.2009.05.051

Van Der Walt, S., Colbert, S. C., \& Varoquaux, G. (2011). The NumPy array: a structure for efficient numerical computation. Computing in Science \& Engineering, 13(2), 22-30.

Waehnert, M. D., Dinse, J., Weiss, M., Streicher, M. N., Waehnert, P., Geyer, S., Turner, R., \& Bazin, P.-L. (2014). Anatomically motivated modeling of cortical laminae. NeuroImage, 93 Pt 2, 210-20. https://doi.org/10.1016/j. neuroimage.2013.03.078

Wallace, M. N., Cronin, M. J., Bowtell, R. W., Scott, I. S., Palmer, A. R., \& Gowland, P. A. (2016). Histological Basis of Laminar MRI Patterns in High Resolution Images of Fixed Human Auditory Cortex. Frontiers in neuroscience, 10(OCT), 455. https://doi.org/10.3389/fnins.2016.00455

Wallace, M. N., Johnston, P. W., \& Palmer, A. R. (2002). Histochemical identification of cortical areas in the auditory region of the human brain. Experimental Brain Research, 143(4), 499-508. https://doi.org/10.1007/s00221002-1014-z

Wasserthal, C., Brechmann, A., Stadler, J., Fischl, B., \& Engel, K. (2014). Localizing the human primary auditory cortex in vivo using structural MRI. NeuroImage, 93 Pt 2(P1), 237-51. https://doi.org/10.1016/j.neuroimage. 2013.07.046

Wehrli, F. W. (1990). Time-of-flight effects in MR imaging of flow. Magnetic resonance in medicine, 14(2), 187-93. https://doi.org/10.1002/mrm.1910140205

Winawer, J., Sayres, R. A., \& Wandell, B. A. (2010). Mapping hV4 and ventral occipital cortex. 10, 1-22. https: //doi.org/10.1167/10.5.1.Introduction

Ye, J. C. (2019). Compressed sensing MRI: a review from signal processing perspective. BMC Biomedical Engineering, 1(1), 1-17. https://doi.org/10.1186/s42490-019-0006-z

Yushkevich, P. A., Piven, J., Hazlett, H. C., Smith, R. G., Ho, S., Gee, J. C., \& Gerig, G. (2006). User-guided 3D active contour segmentation of anatomical structures: significantly improved efficiency and reliability. NeuroImage, 31(3), 1116-28. https://doi.org/10.1016/j.neuroimage.2006.01.015

Yushkevich, P. A., Pluta, J., Wang, H., Wisse, L. E., Das, S., \& Wolk, D. (2016). IC-P-174: Fast Automatic Segmentation of Hippocampal Subfields and Medial Temporal Lobe Subregions In 3 Tesla and 7 Tesla T2-Weighted MRI. Alzheimer's \& Dementia, 12(7S_Part_2), P126-P127. https://doi.org/10.1016/j.jalz.2016.06.205

Zachlod, D., Rüttgers, B., Bludau, S., Mohlberg, H., Langner, R., Zilles, K., \& Amunts, K. (2020). Four new cytoarchitectonic areas surrounding the primary and early auditory cortex in human brains. Cortex, 128, 1-21. https://doi.org/10.1016/j.cortex.2020.02.021

Zaitsev, M., Akin, B., LeVan, P., \& Knowles, B. R. (2017). Prospective motion correction in functional MRI. NeuroImage, 154(November 2016), 33-42. https://doi.org/10.1016/j.neuroimage.2016.11.014

Zaitsev, M., Maclaren, J., \& Herbst, M. (2015). Motion artifacts in MRI: A complex problem with many partial solutions. https://doi.org/10.1002/jmri.24850

Zhang, X., Petersen, E. T., Ghariq, E., De Vis, J. B., Webb, A. G., Teeuwisse, W. M., Hendrikse, J., \& Van Osch, M. J. (2013). In vivo blood T1 measurements at 1.5 T, 3 T, and 7 T. Magnetic Resonance in Medicine, 70(4), 1082-1086. https://doi.org/10.1002/mrm.24550

Zwanenburg, J. J. M., Versluis, M. J., Luijten, P. R., \& Petridou, N. (2011). Fast high resolution whole brain T2* weighted imaging using echo planar imaging at 7T. NeuroImage, 56(4), 1902-7. https://doi.org/10.1016/j. neuroimage.2011.03.046 